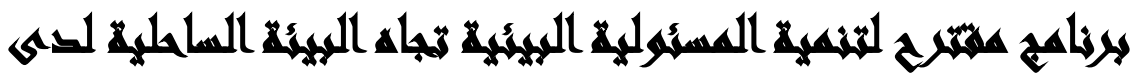

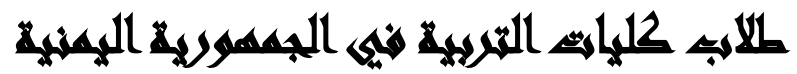

\section{[rr]}

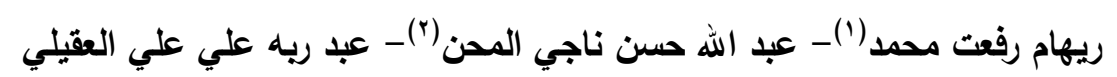

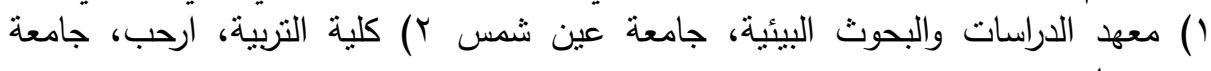

\section{المستخله}

هدف البحث إلى تتمية المسئولية البيئية تجاه البيئة الساحلية لدى طلاب كليات التهات التربية

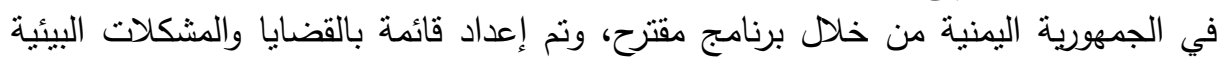

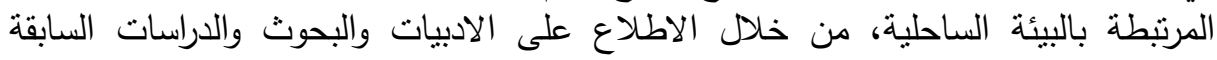

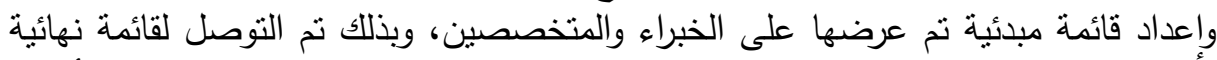

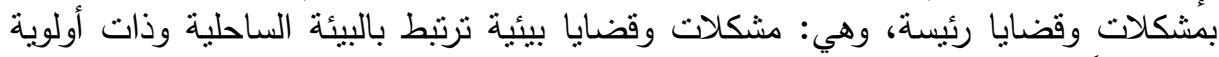

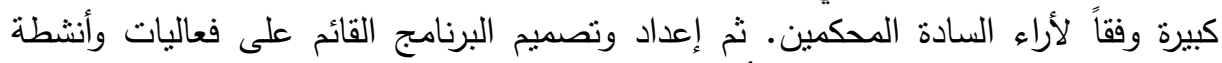

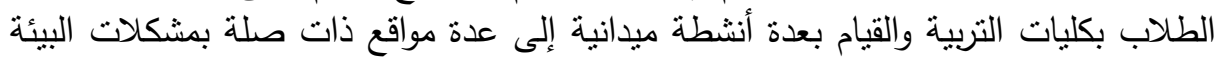

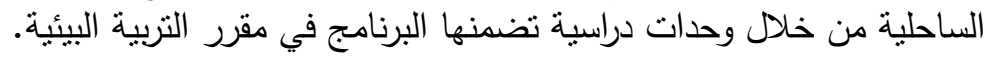

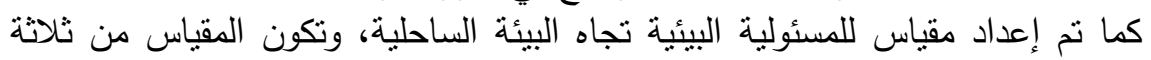

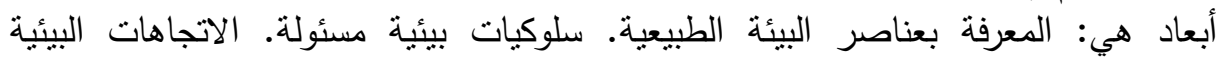
الإيجابية نحو البيئة الساحلية.

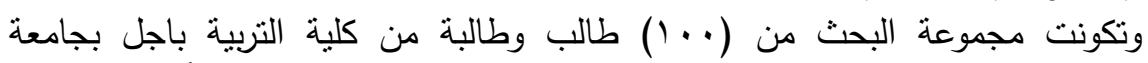

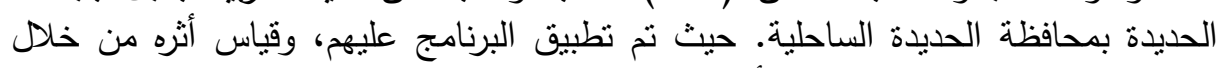

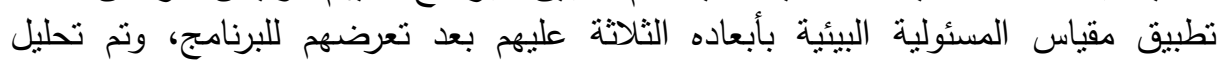

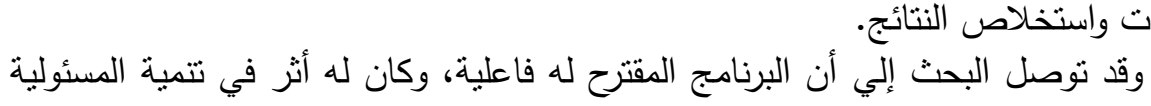

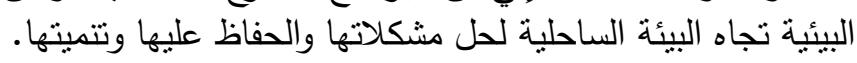




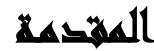

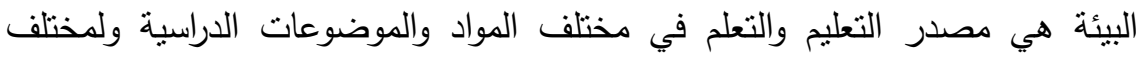
نواحي الحياة الطبيعية، ولا بمكن اعتبار مسئولية الحفاظ على البيئة وتتميتها والاهتمام بها وفهم منطلباتها والمشاركة في صيانتها مسئولية تتظمها اللوائح والقوانين التشريعية والعلمية فحسب وإنما هي مسئولية تربوية إرشادية أخلاقية ذاتية تكمن في نفس الفرد وتتبع من خلال

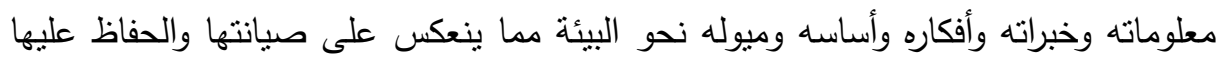
ويظهر ذلك في سلوكهم ومسئولياتهم نحو البيئة. ورغم أن كل من المعلومات والمهارات والاتجاهات والمكون السلوكي نفسه ما هي الا دوافع للفرد نحو المسئولية البيئية حتى يكون عضوا فعالا في المجتمع ويعمل على صيانة البيئة والحفاظ عليها من استتزاف مواردها بل

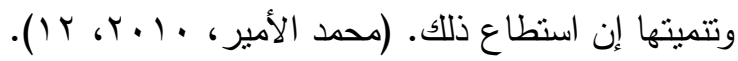

وتمنل المسئولية البيئية (Environmental Responsibility) هدفا أساسيا للتربية البيئية وجانبا مهما من جوانب تعلمها وتتثمل المعلومات الأساسية المرتبطة بالبيئة ومكوناتها والتي تزود الفرد بخبرات متتوعة تؤدى به إلى فهم بيئته، والإسهام في حل مشكلاتها فهي بذلك تعد خطوة سابقة فى إطار إكساب الفرد سلوكيات بيئية مرغوبه، لذا ينادى البعض

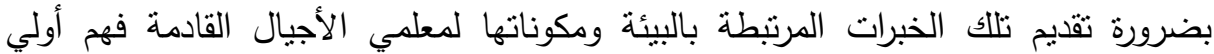

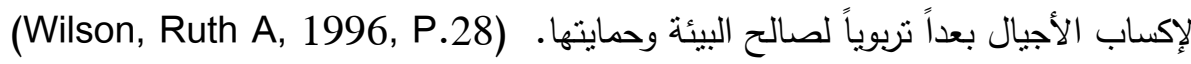
ولا يمكن اعتبار مسئولية الحفاظ على البيئة وتتميتها والاهتمام بها وفهم منطلباتها والمشاركة في صيانتها مسئولية تتظمها اللوائح والقوانين التشريعية والعلمية فحسب ولئه وإنما هي مسئولية تربوية إرشادية أخلاقية ذاتية تكمن في أنفسهر وتتبع من خلال معلوماتهم وخبراتهم

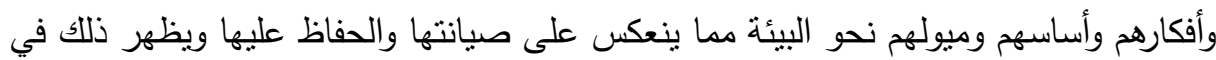
سلوكهم ومسئولياتهم نحو البيئة. ورغم ان كل من المعلومات والمهارات والاتجاهات والمكون السلوكي نفسه ما هي ألا دوافع للفرد نحو المسئولية البيئية حتى يكون عضوا فعالا في المجتمع ويعمل على صيانة البيئة والحفاظ عليها من استنزاف مواردها بل وتتميتها إن استطاع لئه لئه 
والتربية البيئية مسئولية المعلمين جميعًا بغض النظر عن مجالات تخصصاتهم، فالبيئة

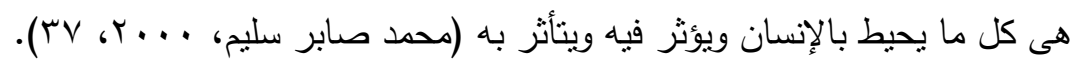
وقد أثنارت بعض الدراسات إلى أهمية تتويع أساليب واستخدام أسلوب الحوار والمناقثنة

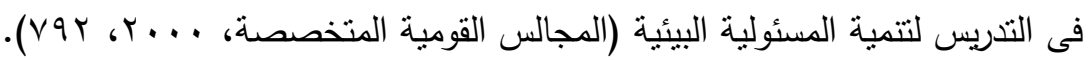
وتتنتر كليات التربية في مختلف الأقاليم والمناطق، ومن أكثر الكليات الجامعية تتوعاً في تخصصاتها العلمية والدراسية، وتضم عديداً من أعضاء هيئة التدريس المؤهلين في مختلف التخصصات النظرية والعلمية، وفوق هذا وقبله فإن هذه الكليات معنية بإعداد وتأهيل

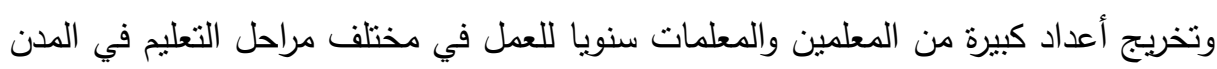
والقرى؛ ومن ثم فإن مخرجات هذه الكليات من حيث (الإعداد) و (الأعداد) ستتفاعل علمياً

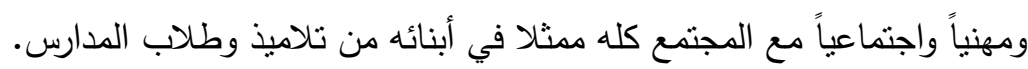

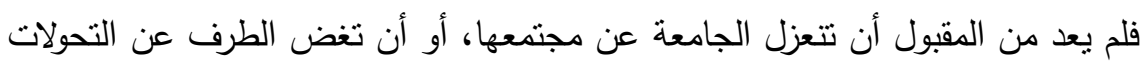

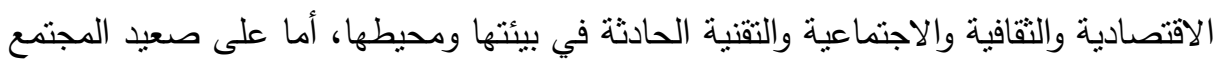
نفسه، فقد أضحت التوقعات المجتمعية بشأن دور الجامعة أكثر تعاظما وتفاعلا مع الجامعات ومئه في ضوء ما تملكه الجامعات من خبرات علمية وبشرية، وما تتتجه من بحوث ودراسات يمكن أن تسهم في حل كثير من المشكلات ومواجهة كثير من القضايا العامة والبيئية خاصة التي مني يعيشها المجتمع المحبط. وللجمهورية اليمنية ساحل طويل على كل من خليج عدن والبحر العربي من الجنوب،

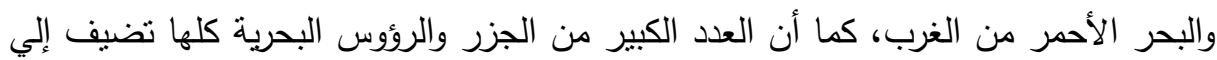

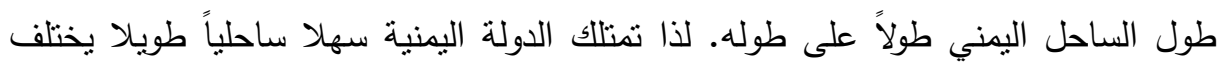
عرضه من منطقة إلي أخري حيث ينسع أحياناً ويضيق أحياناً بل ويختفي تماما في بعض لئه

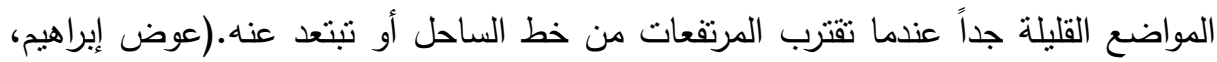

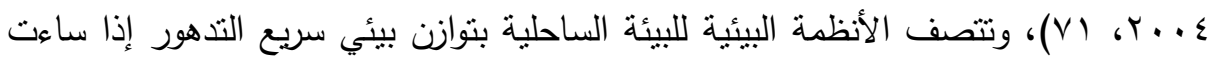

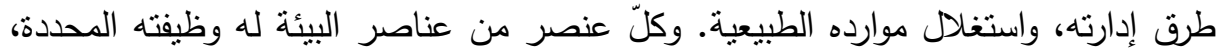

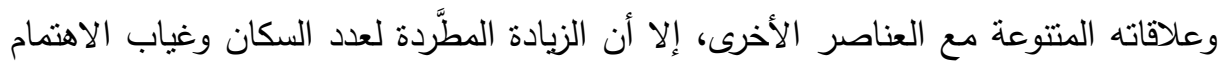

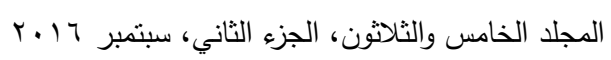


بالبيئة أحدثا استغلالاً غير واعٍ وضغوطاً منواصلةً على موارد البيئة؛ فنجم عن ذلك خللّ في الأنظمة البيئية يصل إلى مستوى التدهور في العلاقات البيئية، على ان مستويات ذلك التدهور تختلف من بلد إلى آخر اليمن كغيرها من البلان النامية حديثة عهد بالإدارة البيئية ولا تزال أطرها التشريعية والمؤسسية والتكنولوجية بحاجة الى تحسين وتطوير إدارة الموارد الطبيعية حيث ان شحة بعض هذه الموارد منل موارد المياه في بعض المناطق وزيادة معدل النلوث في ولهيه

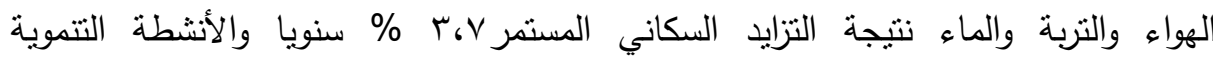
والاجتماعية المختلفة للسكان كل هذا أدى إلى تزايد الاهتمام بقضايا البيئة منذ بداية الثمانينات

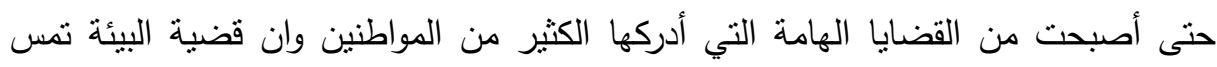
الأجيال الحالية والقادمة كما انها ارتبطت بالتتمية ويتطلب أخذها بالاعتبار لتحقيق تتمية قابلة

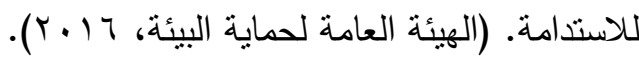

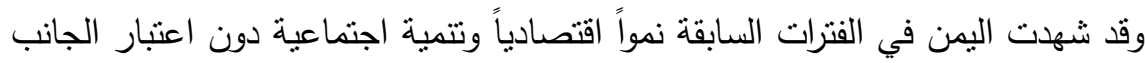
البيئي، وتواجه البلاد عدداً من المشاكل البيئية، ويعتبر هذا الوضع غير المتوازن بين الإنسان

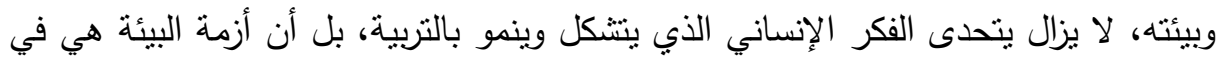

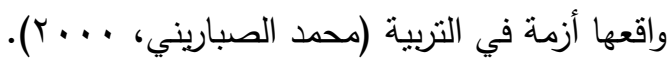
وتُعد المناطق الساحلية في اليمن نراث طبيعي وتقافي مشترك ايضاً لشعوب البحر

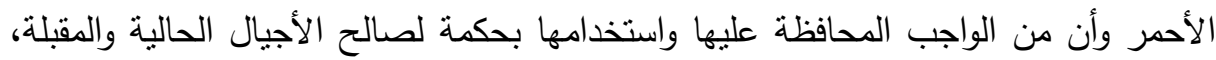
وإذ يساورها القلق بسبب زيادة الضغط البشري على البيئة الساحلية في اليمن والذي يهدد طبيعتها الهشة، وإذ ترغب في إيقاف تدهور المناطق الساحلية وفي الحدث بشكل واسع من لن فقد التتوع البيولوجي للنظم الإيكولوجية الساحلية، فمن المخاطر الملحة بالبيئة الساحلية باليمن

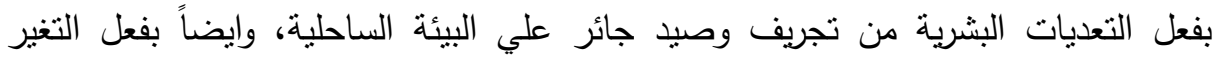

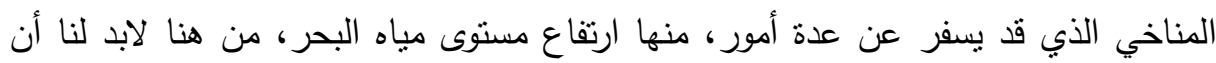

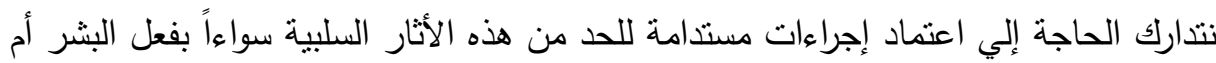

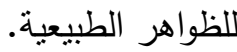


وبالتالي فان نتمية المسؤولية البيئية تجاه البيئة الساحلية يجب أن يكون هدف من أهداف

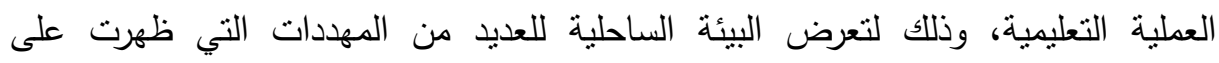
عناصرها وذلك من خلال تعرضها لمياه الصرف الصحي وتتويه منظر الساحل، والبناء العشوائي، وعدم الاهتمام بمناطق الثعاب المرجانية، واستتزاف الأصداف البحرية، ودفن

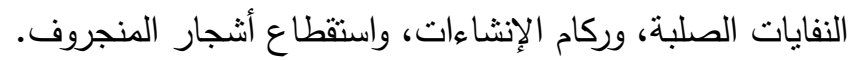
فقد أورد الدستور اليمني في نص مادته الخامسة والثلاثثن بأن (حماية البيئة مسئولية الدولة والمجتمع، وهو واجب ديني ووطني على كل مواطن) كذلك فمن هنا جاءت فكرة البحث

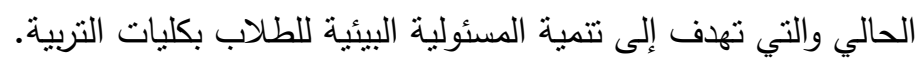

\section{هill}

تم إجراء دراسة استطلاعية تم التساؤل من خلالها على مدى تضمن الدليل موضوعات

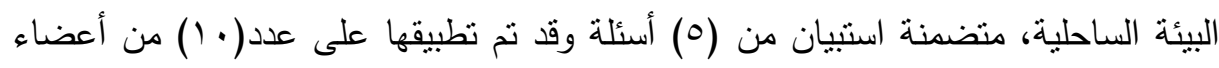

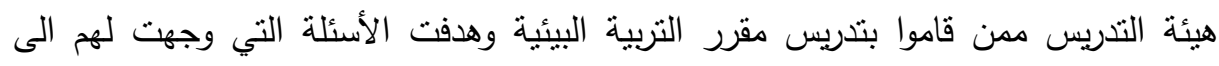

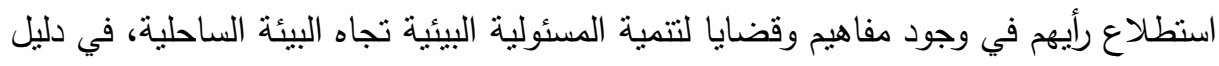
الجامعة وبخاصة مقرر التربية البيئية وتبين من نتائج الدراسة الآتي:

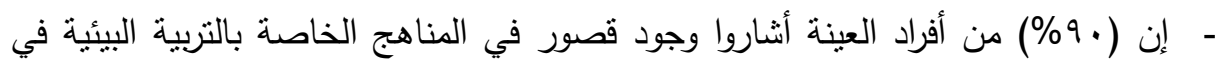

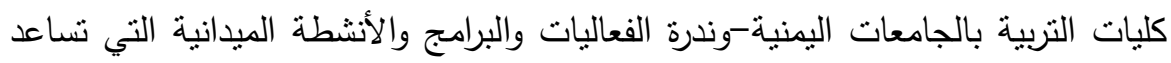

$$
\text { على ربط الطلاب ببيئتهم الساحلية. }
$$

- أن (· (. 1\%) من أفراد العينة أثناروا إلى ضرورة تقديم تصور مقترح لمقرر التربية البيئية اتجاه البيئة الساحلية، والعمل به ليسهم في معرفة الطلاب لطبيعة العلاقة بين الإنسان

والبيئة الساحلية.

وعلى الرغم من الاهتمام الدولي بالمشكلات البيئية بالبيئة الساحلية حيث أثنار مؤتمر

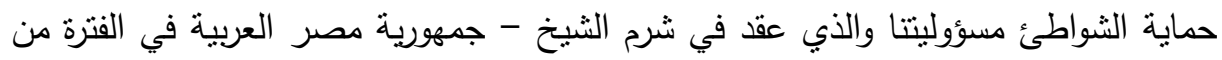

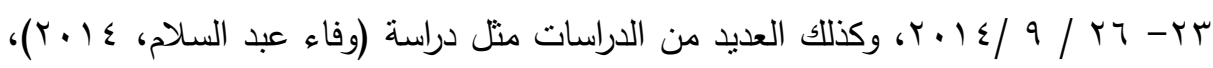

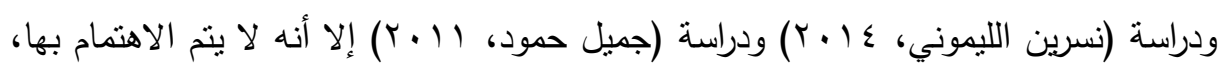

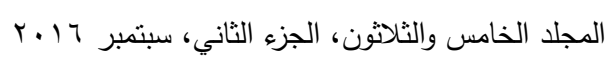


حيث قام الباحثون بمراجعة أدلة كليات التربية بجامعة صنعاء باليمن والتي أظهرت أنها لا

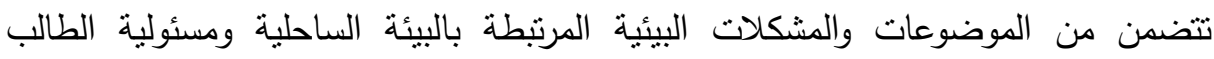
تجاهها.

وبذلك أمكن تحديد مشكلة البحث الحالي في قصور المسئولية البيئية تجاه البيئة الساحلية لدى طلاب كليات التربية في الجمهورية اليمنية.

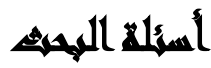

"ما البرنامج المقترح لتنمية المسئولية البيئية تجاه البيئة الساحلية لدى طلاب كليات

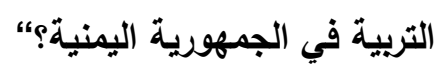
ويتفرع عن السؤال الرئيس الأسئلة التالية:

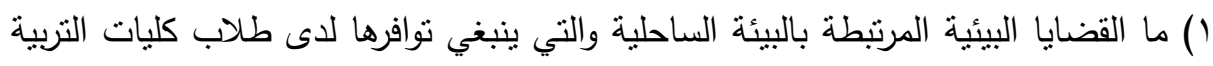

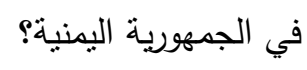

r) ما مدى تضمين مقرر التربية البيئية بالقضايا البيئية المرتبطة بالبيئة الساحلية، لدى طلاب

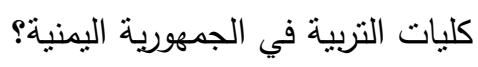

r) ما البرنامج المقترح لتتمية المسؤولية البيئية اتجاه البيئة الساحلية لدى طلاب كليات التربية

$$
\text { في الجمهورية اليمنية؟ }
$$

ع) ما فاعلية البرنامج المقترح في تتمية المسؤولية البيئية اتجاه البيئة الساحلية لدى طلاب

$$
\text { كليات التربية في الجمهورية اليمنية؟ }
$$

\section{همبهـ المهيه}

هدف البحث الحالي إلى: تتمية المسئولية البيئية تجاه البيئة الساحلية لدى طلاب كليات

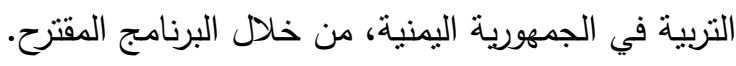




\section{أهمية الهبهث}

قد تقيد نتائج البحث الحالي فيما يلي: ا. مخططي المناهج الجامعية: وذلك من خلال وضع إطار عام لكيفية إعداد برامج تساهم في تتمية المسؤولية البيئية اتجاه البيئة الساحلية.

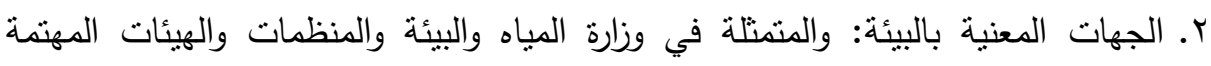
بالبيئة، وذلك من خلال ما ستسفر عنه نتائج الدراسة.

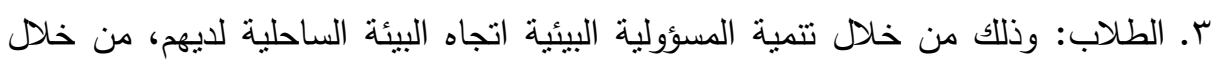

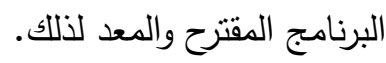

\section{هنهمج المهيد}

استخدم البحث الحالي المنهجين الآتيين: المنهج الوصفي (Descriptive approach): لتحليل محتوى المقررات الحالية لمعرفة مدى تتاولها للموضوعات البيئية ومشكلات البيئة الساحلية. المنهج شبه التجريبي: (Quasi-experimental approach) في تجريب بعض الموضوعات التي يتضمنها البرنامج المقترح لمقرر التربية البيئية على مجموعة من طلاب كليات التربية بالمحافظات الساحلية (كلية التربية باجل- جامعة الحديدة)، وذلك باستخدام

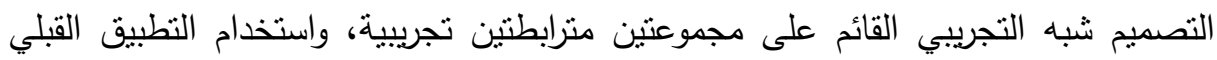
والبعدي لأدوات القياس المتمثلة في (مقياس المسئولية البيئية).

\section{Aهو}

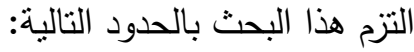

الحدود الجغرافية (المكانية): كليات التربية بالمحافظات الساحلية بالجمهورية اليمنية. الحدود البشريةة: مجموعة من طلاب كلية التربية، باجل- بجامعة الحديدة - بمحافظة الحديدة في الجهة الغربية للجمهورية اليمنية على ساحل البحر الأحمر • ويبلغ عددهم (·. (1) طالب: . . 1 طالب من كلية التربية باجل (بمدينة باجل اليمنية) جامعة الحديدة

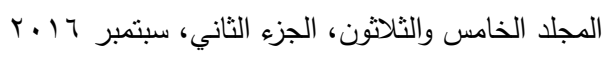


الحدود الزمنية: العام جامعي(10 • ب/ 1 • ب) وهي فترة جمع البيانات وتطبيق البرنامج

المقترح. مقرر التربية البيئية (للمستوى الرابع) بكليات التربية (مقرر اختياري)

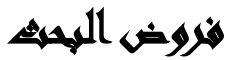

يحاول البحث الحالي التحقق من صحة الفروض التالية: الفرض الرئيس: يوجد فرق دال إحصائياً عند مستوى دلالة (1 ., .) بين متوسطي درجات

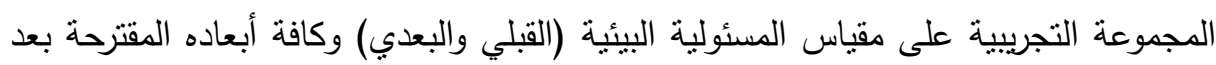
تطبيق البرنامج المقترح لصالح التطبيق البعدي. ويتفرع عن هذا الفرض الآتي:

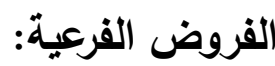
أ. يوجد فرق دال إحصائياً عند مسنوى دلالة( (.,.) بين متوسطي درجات المجموعة

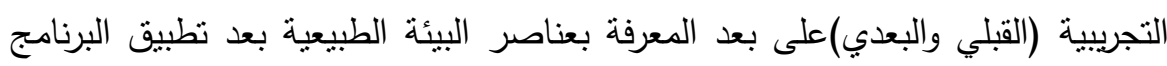
المقترح لصالح النطبيق البعدي. ب.يوجد فرق دال إحصائياً عند مستوى دلالة (1.,.•) بين متوسطي درجات المجموعة التجريبية (القبلي والبعدي) على بعد سلوكيات بيئية مسئولة بعد تطبيق البرنامج المقترح لصالح النطبيق البعدي. ج. يوجد فرق دال إحصائياً عند مستوى دلالة (1.,.•) بين منوسطي درجات المجموعة

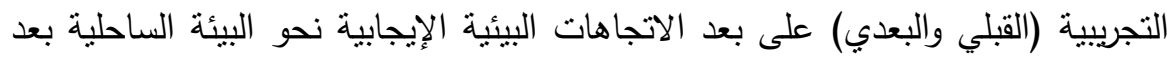

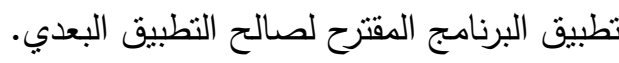




\section{همطلحاهي الهحمث}

المسئولية البيئية Responsibility) يعرف"ابرو"

(Ebreo:2004): المسؤولية البيئية بأنها:النشاط أوالفعل الذي يقوم به الفرد للمحافظة على البيئة ويتم اكتساب هذا السلوك من خلال بعض المتغيرات كالمعرفة والاتجاهات.

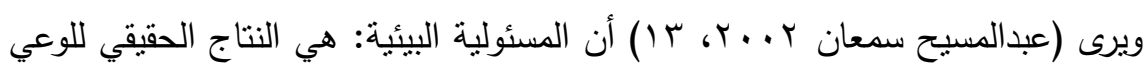

البيئي ظالناشئ أصلاً من تغير المعارف والاتجاهات نحو البيئة وكذلك التغير الحادث في لهي السلوك البيئي الموجب، فالسلوك البيئي الموجب أو السوي هو السلوك المسؤول، ويُعد هذا التعريف كتعريف إجرائي للبحث الحالي.

وتُعرف المسئولية البيئية إجرائياً في البحث الحابدي لحالي بأنها: محصلة استجابات طلاب كلية التربية نحو محاولة المعرفة عن البيئة الساحلية والاتجاه نحو حمايتها ومن ثم القيام بأفعال وتصرفات لصالح البيئة الساحلية وحل مشكلاتها، وتقاس المسئولية البيئية إجرائيا بالدرجة التي يحصل عليها الطالب على مقياس المسئولية البيئية (المستخدم بالبحث الحالي). البيئة الساحلية: (Environmental Responsibility): ووفق (تقرير الوضع البيئي

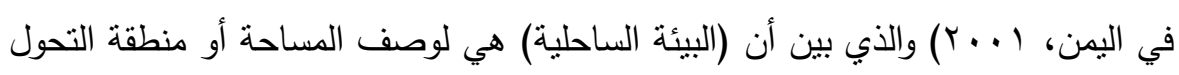

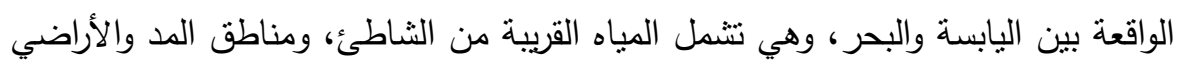
الواسعة، حيث تستطيع العديد من الأحياء والكائنات التأقلم مع هذه الظروف البئئية الفئية الفريدة.

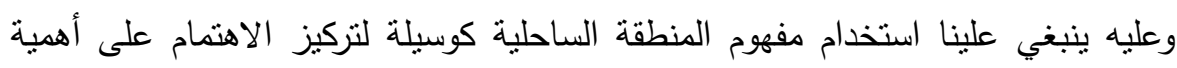
إيجاد استراتيجية أو تحديث خطط وترتيبات إدارية تأخذ بعين الاعتبار الترابط القائم بين النظم البيئية والساحلية والأراضي الجافة.

\section{إلجراعاهت المهيد}

للإجابة عن السؤال الأول من أسئلة البحث والذي ينص على: "ما القضايا البيئية المرتبطة بالبيئة الساحلية والتي ينبغي نوافرها لاى طلاب كليات التربية في الجمهورية

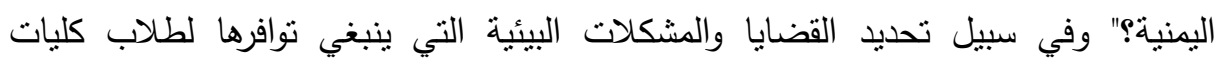

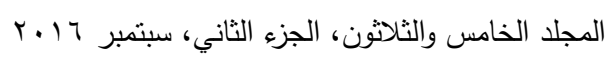




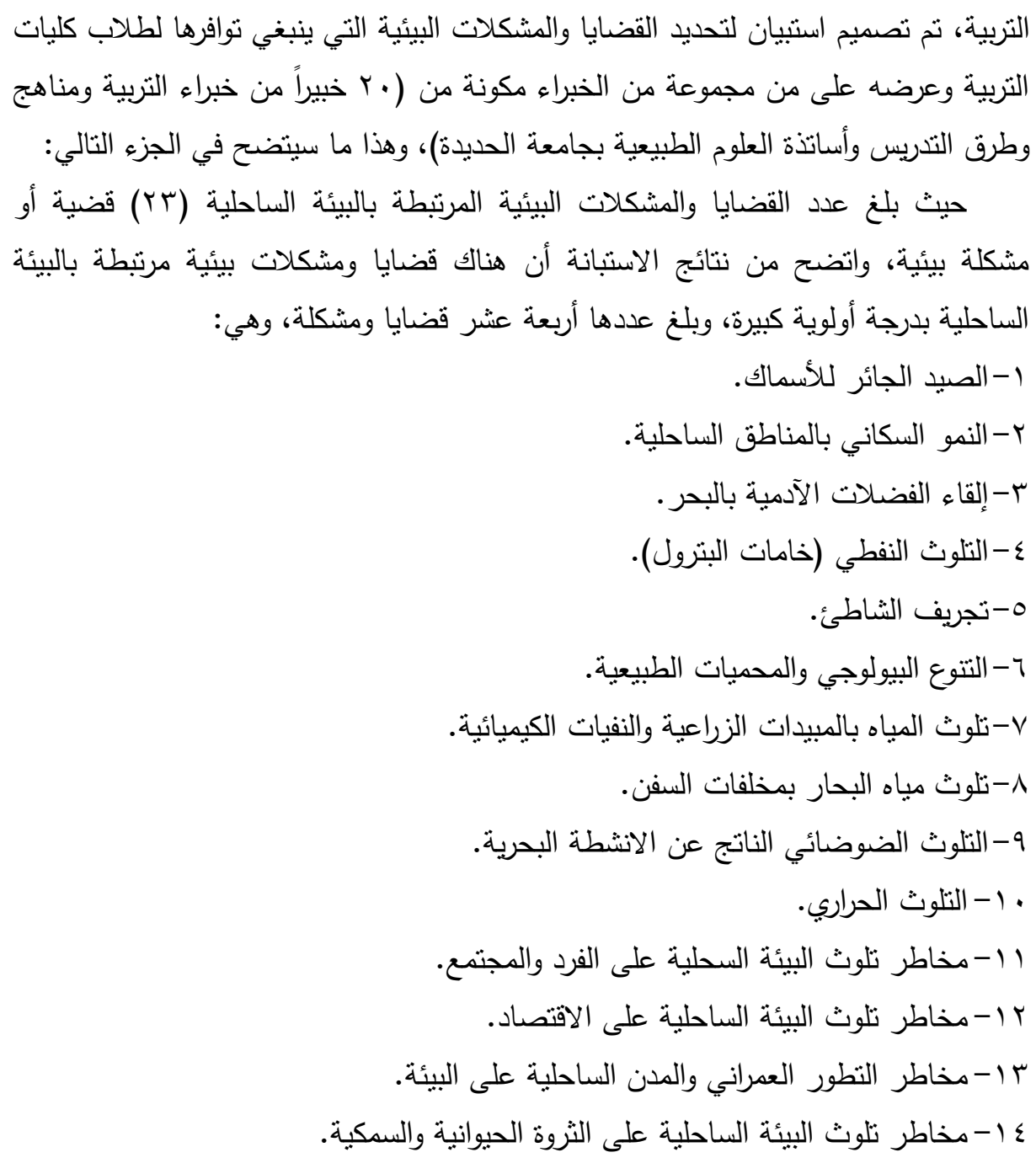

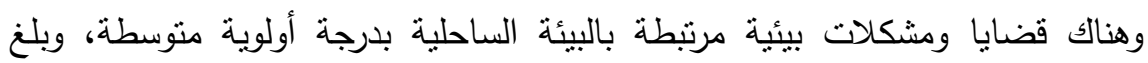

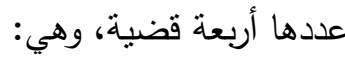
ا ـ ب نزح مياه الثاطئ الرملي.

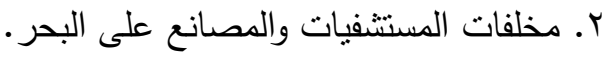




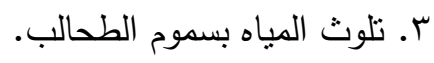
ع. التلوث الإشعاعي.

وهناك قضايا ومشكلات بيئية مرتبطة بالبيئة الساحلية بدرجة أولوية صغيرة، وبلغ عددها خمسة قضايا، وهي: 1-زحف الكثبان الرملية.

$$
\begin{aligned}
& \text { r-ردم الثاطئ. } \\
& \text { ب- الصرف الصحي. } \\
& \text { ع-تلوث المياه الجوفية. } \\
& \text { ه-قناديل البحر . }
\end{aligned}
$$

ومن خلال ما سبق يتضح أن جميع القضايا والمثكلات البيئية المرتبطة بالبيئة الساحلية

بالقائمة سواء التي لها درجة كبيرة من الأهمية، او التي لها درجة منتوسة أو كبيرة، فهي من وجهة نظر السادة الخبراء مناسبة لطلاب كليات التربية، الا أن بعضها يحتاج إلى إدماج وتعديل في الصياغة اللغوية والحذف لبعض منها، وهذا ما تم الوصول إليه في الصورة النهائية لقائمة القضايا والمشكلات البيئية المرتبطة بالبيئة الساحلية. الصورة النهائية لقائمة القضايا والمشكلات المرتبطة بالبيئة الساحلية وينبغي تتمية المسئولية البيئية تجاهها لطلاب كليات التربية باليمن. بناءاً على ما أبداه السادة الخبراء من ملحوظات، تم إجراء التعديلات اللازمة، ثم ثاء عرضها مرة أخري على السادة المشرفين حتى أصبحت القائمة في صورتها النهائية معدة لاستخدامها في مجال البحث. 
جدول(1): قائمة القضايا والمشكلات البيئية المرنبطة بالبيئة الساحلية في الثكل النهائي

\begin{tabular}{|c|c|}
\hline المشكلة أو القضية البيئية التي ترتبط بالبيئة الساحلية (ذات الأولوية الكبيرة) & م \\
\hline النمو السكانى بالمناطق الساحلية & 1 \\
\hline تجريف الثاطئ & r \\
\hline تلوث المباه بالمبيدات الزراعبة والنفبات الكبمبائبة & $r$ \\
\hline 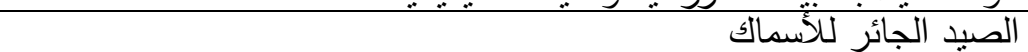 & $\varepsilon$ \\
\hline تلوث مياه البحار بمخلفات السفن & 0 \\
\hline التلوث الضضوضائي الناتج عن الانشطة البحرية & 7 \\
\hline التلوث الحراري & $\mathrm{V}$ \\
\hline التتوع البيولوجى والمحميات الطبيعية & $\Lambda$ \\
\hline التلوث النفطى (خامات البترول) & 9 \\
\hline إلقاء الفضلات الآدمية بالبحر & 1 . \\
\hline مخاطر تلوث البيئة السحلية على الفرد والمجتمع & 11 \\
\hline مخاطر تلوث البيئة الساحلية على الاقتصاد & Tr \\
\hline مخاطر التطور العمراني والْمدن الساحلية على البيئة & $1 \pi$ \\
\hline مخاطر تلوث البيئة ال & $1 \varepsilon$ \\
\hline
\end{tabular}

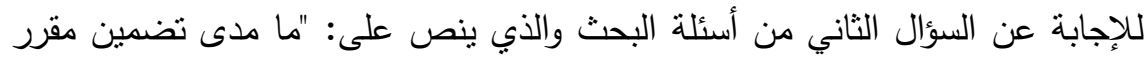
التربية البيئية بالقضايا والمشكلات البيئية المرتبطة بالبيئة الساحلية لدى طلاب كليات التربية في الجمهورية اليمنية؟" تم إعداد استمارة تحليل المحتوي لمعرفة مدي تضمين هذه القضايا والمشكلات مقرر التربية البيئية بكليات التربية. ومرت عملية التحليل بالخطوات الآتية: - تم تحديد المقرر (الكتاب) الذي يتضمن ذات الموضوعات، وكان المقرر بعنوان: (التربية

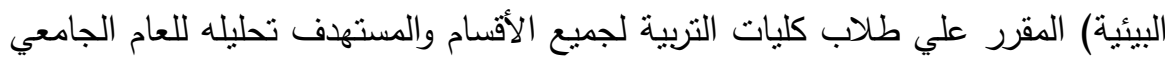

$$
\cdot(r \cdot 1 T / Y \cdot 10)
$$

- قراءة المقرر بشكل كامل للتعرف على محتوياته والأفكار الأساسية المتضمنة في المادة

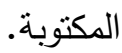

- تحديد الفقرات التي تتضمن القضايا والمشكلات البيئية المتضمنة بالقائمة. - تم استخدام الفقرة كوحدة تحليل. - تحديد المشكلات الفرعية التي تتمي وتحث على المسئولية البيئية تجاه هذه القضايا والمشكلات المرتبطة بالبيئة الساحلية. 
- تحديد المشكلات المتعلقة بالجوانب البيئة الساحلية. ما إذا كان تتتاولها بصورة صريحة أم ضمنية في كل فقرة من الفقرات.

- تسجيل نتائج التحليل في استمارة التحليل باستخدام الحزم الإحصائية. - الوضع الحالي لمقرر (التربية البيئية) لطلاب كليات التربية باليمن لجميع المستويات. - نم إعداد قائمة تحليل المحتوى في ضوء مكونات قائمة القضايا والمشكلات المرتبطة بالبيئة الساحلية التي سبق إعدادها وتم عرضها علي السادة الخبراء(الدحكمين). جدول رقم(ץ): نتائج تحليل مقرر (التربية البيئية) المقرر علي طلاب كليات التربية باليمن

\begin{tabular}{|c|c|c|c|c|c|c|}
\hline \multirow{2}{*}{$\%$} & \multirow[b]{2}{*}{ مج } & \multicolumn{2}{|c|}{ ضمن } & \multicolumn{2}{|c|}{ صريجِ } & \multirow{2}{*}{ المشاكل البيئية الفرعية } \\
\hline & & $\%$ & ت & $\%$ & ت & \\
\hline- & 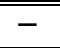 & 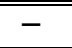 & - & 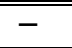 & - & النمو السكاني بالمناطق الساحلية \\
\hline 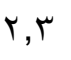 & 1 & 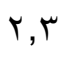 & 1 & - & - & تجريف الشاطئ \\
\hline- & - & - & - & - & - & تلوث المياه بالمبيدات الزراعية والنفيات الكيميائية \\
\hline- & - & - & - & - & - & الصبد الجائر للآسماك \\
\hline$r, r$ & 1 & $r, r$ & 1 & - & - & تلوث مباه البحار بمخلفات السفن \\
\hline- & - & - & - & - & - & التلوث الضوضائي الناتج عن الانشطة البحرية \\
\hline$\varepsilon, 7$ & r & $\varepsilon, 7$ & $r$ & - & - & التلوث الحراري \\
\hline$\xi, 7$ & r & $\varepsilon, 7$ & r & - & - & التتوع البيولوجى والمحمبات الطبيعية \\
\hline$r, r$ & 1 & $r, r$ & 1 & - & - & التلوث النفطي (خامات البترول) \\
\hline$r, r$ & 1 & - & - & $r, r$ & 1 & إلقاء الفضلات الآدمبة بالبحر \\
\hline- & - & - & - & - & - & مخاطر تلوث البيئة السحلية على الفرد والمجتمع \\
\hline- & - & - & - & - & - & مخاطر تلوث البيئة الساحلية على الاقتصاد \\
\hline- & - & - & - & - & - & مخاطر التطور العمرانى والمدن الساحلية على البيئة \\
\hline- & - & - & - & - & - & مخاطر تلخية والسمكية البيئة الساحلية على الثروة \\
\hline
\end{tabular}

وأظهرت النتائج ما يلي: نتائج تحليل محتوي مقرر التربية البيئية في برنامج إعداد المعلم الحالي لثلاث كليات تربوية، أظهرت: عدم شمولية محتوي المقرر لمكونات وعناصر المسئولية البيئية أيضا سواء ضمنياً أو بطريقة صريحة الوعي بالمشكلات وقضايا البيئة الساحلية، الاتجاه نحو حماية وصبانة البيئة الساحلية، السلوك البيئي المسئول تجاه البيئة الساحلية، بلئه اتخاذ القرار البيئي حول حماية وتتمية البيئة الساحلية، المشاركة في حل مشكلات تلوث البئه البئة 
فهو يقتصر على ذكر بعض الموضوعات الضمنية البسيطة المرتبطة بالبيئة الساحلية، ويخلو من معظم قضايا ومشكلات البيئة الساحلية اليمنية، وكيفية تحمل المسئولية البيئية تجاه هذه المشكلات والقضايا، ولا يراعي المقرر كيف يمكن اكتساب السلوكيات البيئية المسئولة تجاه البيئة الساحلية.

ونتيجة التحليل الحالية اتفقت مع ما بينته دراسات بمنية لــ: عبد الله غالب عبد الكريم

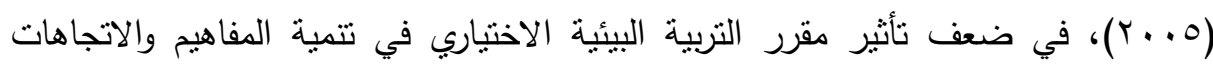

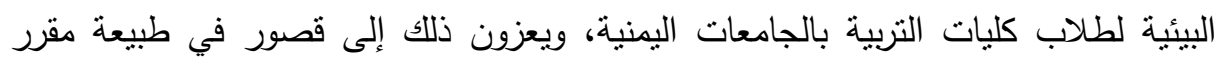

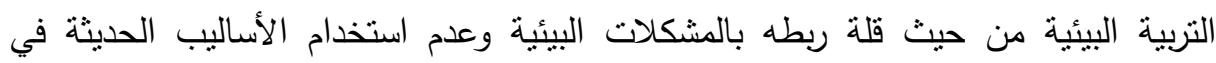
تدريسه.

للإجابة عن السؤال الفرعي الثالث: "ما البرنامج المقترح لتتمية المسئولية البيئية تجاه

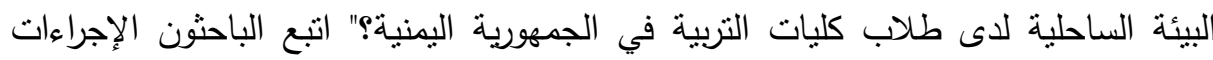
التالية:

يهدف البرنامج المقترح لتمية المسئولية البيئية لدى الطلاب (المعلمين) بكليات التربية

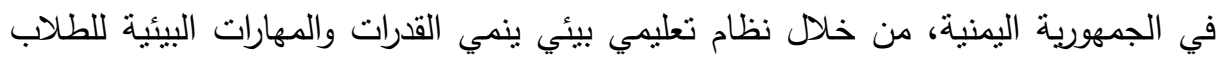

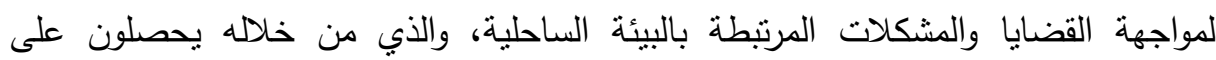

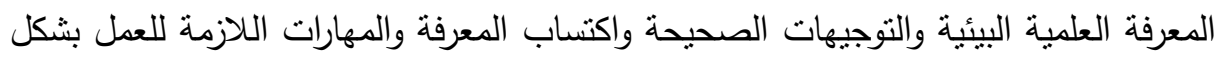
فردي أو جماعي في حل المشكلات البيئية الساحلية القائمة والعمل أيضاً قدر الإمكان وقائياً دون حدوث مشكلات بيئية جديدة تهدد البيئة الساحلية.

\section{الأهداف الإجرائية للبرنامج:}

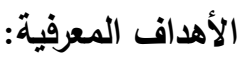

1 . يحدد الثروات الطبيعية في بيئته الساحلية وسبل المحافظة عليها.

r r بصف مقومات التوازن الطبيعي في بيئته. r. يستتنج المشاكل التي تعانيها البيئة الساحلية والأخطار التي تهددها. ع. يوضح العلاقات القائمة بين عناصر ومكونات البيئة الساحلية. 
0. يضع خططاً عملية لمحاولة علاج مشكلات البيئة الساحلية. 7. يحدد التأثيرات البشرية على بعض الجوانب المرتبطة بالبيئة الساحلية.

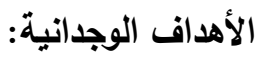
ا • يعي أهية المشاركة في حل المشكلات القائمة في البيئة الساحلية. r. يعي أن الكائن الحي يتأثز بما حوله الهئه

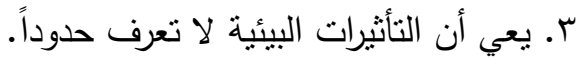
ع. يقدر أهمية البيئة الساحلية على الاقراد المحبطين بها. ه. يقدر العلاقات الني تربط بين عناصر البيئة عامة والبيئة الساحلية خاصة. 7. يشعر بمسئوليته كفرد تجاه المحافظة على البيئة الطبيعية والمشيدة. V. يؤمن بأن للأجيال القادمة الحق في الموارد الحالية وبيئة خالية من التلوث. ^. يقدر الجهود المبذولة للحد من المخلفات والنفايات. 9. يقدر قيمة الاستخلال الأمنل للموارد البيئية. الأهداف المهارية السلوكية:

1. يحلل المشاكل البيئية ليدرك أسبابها وطرق التعامل معها. r. يكتسب مهارة التوصل إلى قرار سليم قائم على دراسة وفحص البدائل المختلفة. r. يساهم في حل بعض المشاكل والقضايا في البيئة الساحلية. ع. يكتسب مهارة تتظيم المعلومات الخاصة بالقضايا والمشكلات البيئية. 0. يساهم في وضع خطط لمعالجة المشاكل البيئية. T. يتخذ قرارات مناسبة تساهم في الحد من التعدي على بيئة اليمن الساحلية. V V V Vتسب مهارة العمل في مجموعات صغيرة. ^. يكتسب مهارة كتابة البحوث والتقارير والمقالات 9. يستخدم شبكة المعلومات الدولية في التعرف على الجديد لمعالجة قضايا البيئة. 
محتوي البرنامج: تم الاعتماد في بناء محتوي البرنامج على أولوبات القضايا والمشكلات البيئية المرتبطة بالبيئة الساحلية والتي حصلت في مجملها على أولوية كبيرة من السادة المحكين على استطلاع الرأي الذي ثم إعداده من قبل، وايضاً في ضوء خطة فئة العمل الوطنية للبيئة التي قابم بها مجلس حماية البيئة اليمني بالتعاون مع بعض مكاتب البيئة البئة الدولية (تقرير

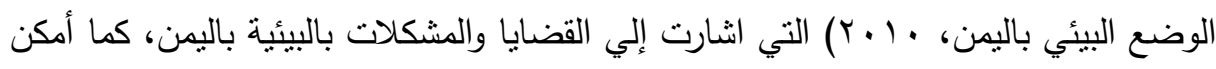

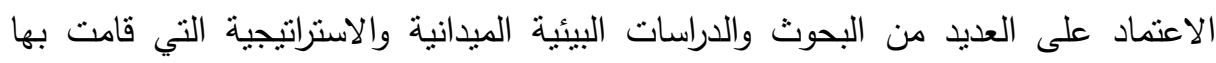

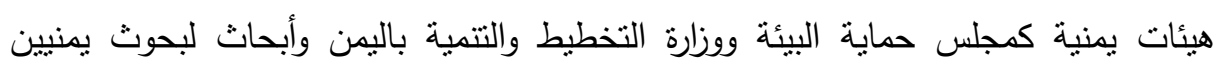

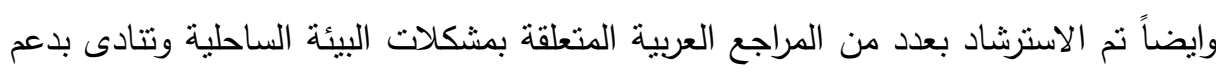
وتتمية السلوك البيئي المسئول.

وقد اتبع البحث الإجراءات الثالية في تحديد مصادر محتوي البرنامج:

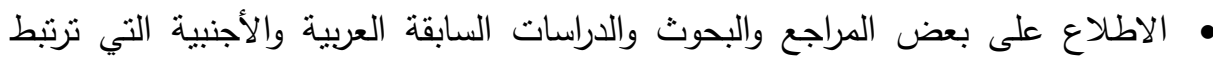
بمجال البحث الحالي للاستفادة منها. • الدخول على بعض المواقع عبر شبكة الانترنت التي تتاولت البيئة اليمنية ودراسة البيئة الساحلية التي تتاولها البحث الحالي، وكيفية مواجهة المشكلات البيئية التي تتعرض لها.

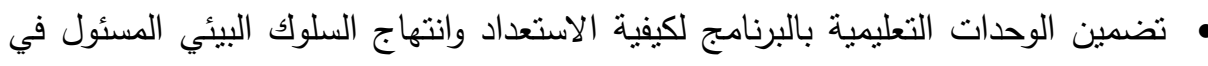
عند التعرض لمشكلات وقضايا البيئة الساحلية؛ لما للتربية البيئة من جزء وقائي وأهميته في مساعدة الأفراد على مواجهة ما قد يطرأ من حوادث ومشكلات بيئية للبيئة الساحلية،

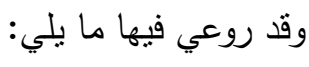

- ارتباطها بالمحتوى العلمي للوحدة التعليمية، وبأهداف البرنامج في تتمية المسئولية البيئية

تجاه البيئة الساحلية.

$$
\text { - - دقة المعلومات وتتابعها. }
$$

- بساطة الأسلوب والتشويق بحيث يتمكن الطلاب بكليات التربية من الإفادة والاستمتاع.

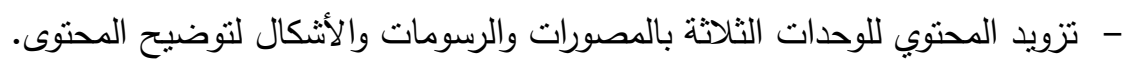


• تحكيم الوحدات الثلاثة للبرنامج: تم عرض الوحدات على مجموعة من المتخصصين في المناهج وطرق التدريس وفي علوم البيئة. • تعديل كل وحدة من الوحدات الثلاثة وفق نوجيهات وملاحظات المحكمين، ثم إخراجها بالثكل النهائي.

مكونات البرنامج للطلاب بكليات التربية: بسير مضمون هذا البرنامج في اتجاه عدم وجود فواصل بين الموضوعات المختلفة فيه، وحيث أن هناك عوامل أخري قد تساعد في تتمية المسئولية البيئية لاى المتعلمين (طلاب كليات التربية باليمن)، لذا فالبرنامج ينتاول هذه

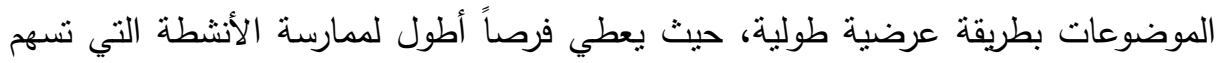
في تتمية المسئولية البيئية المقصودة. وتم تصنيف البرنامج في ثلاثة وحدات تعليمية نظمت كل وحدة على أساس: الأهداف،

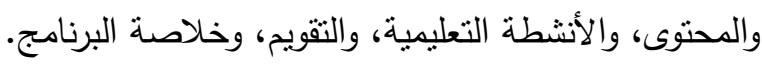
الوحدة الأولي: البيئة مسئوليتتا جمعياً

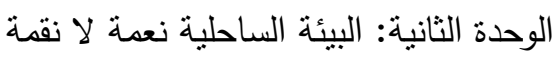

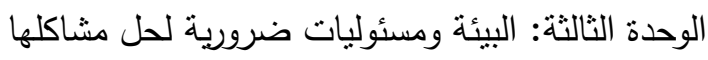
الوحدة الأولي بعنوان: البيئة مسئوليتنا جمعياً أهمية اختيار موضوع الوحدة وتسميتها: - لأنها الوحدة التي تركز على المعارف والمفاهيم الأساسية التي يجب أن يعرفها الفرد عن البيئة

- تتيح تتاول الأهداف المعرفية لبرنامج لتتمية المسئولية البيئية.

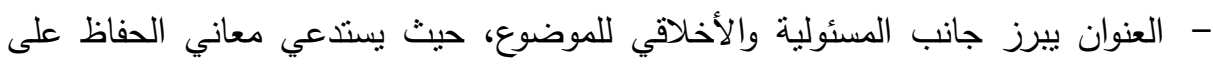

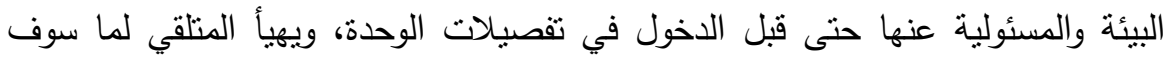




\section{أهم الأهداف الإجرائية لهذه الوحدة:} ا ب بذكر مفهوم البيئة ومكوناتها.

r r بذكر عناصر المسئولية البيئية تجاه عناصر البيئة من حولنا. r. يعي أهمية الحفاظ على التوازن بين البيئات المختلفة. ـ ـ ينتبأ بما يمكن أن يحدث في حالة الاختلال بالتوازن البيئي.

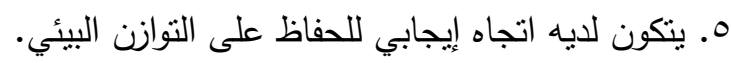
حيث تتتاول هذه الوحدة: الموضوعات الأساسية المتعلقة بالبيئة ومنها تعريف البيئة، تصنيف لئئي البيئات، الموارد البيئية وتصنيفها (موارد بيئية دائمة ومتجددة وغير متجددة)، مفهوم النظام البيئي، مكونات النظام البيئي (حية وغير حية) وما يحتوي عليه من نوازن، المسئولية البيئية والعناصر التي تتألف منها.

هذه الموضوعات وما يمكن أن تحتويه من مسئوليات ترتبط بالحفاظ على البيئة،

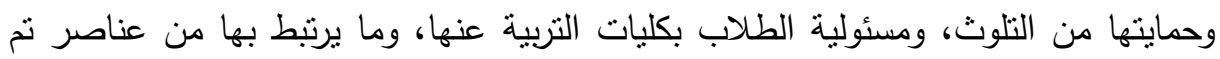

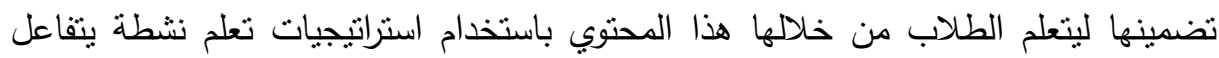
فيها الطلاب أنفسهم (كالتعلم التعاوني، والاستقصائي، والميداني، الذاني، والعصف الذهني).

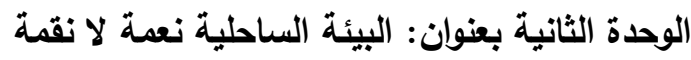
أهمية اختبار الوحدة وتسميتها: - لأن البيئة الساحلية أحد أهم الموارد البيئية الهامة والذي ترتبط بحياة الناس في اليمن.

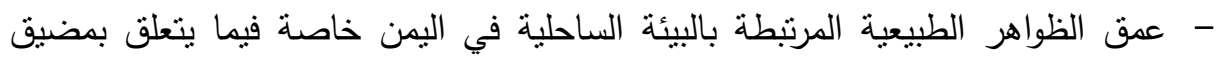
باب المندب بالبحر الأحمر وخليج عدن.

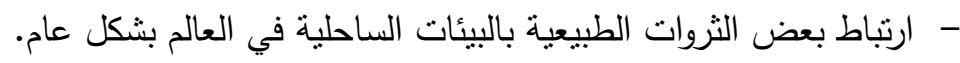

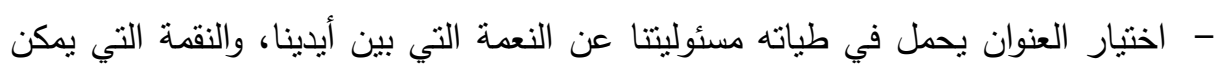

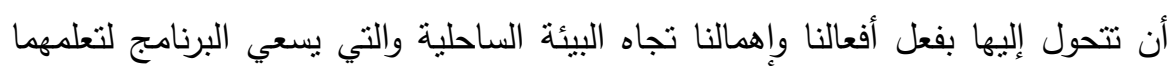
من هنا فالعنوان يحمل دلالة قيمية تيسر توصيل المفاهيم التي يسعي البرنامج لتوصيلها. 
أهم الأهداف الإحرائية لتعلم هذه الوحدة:

ا • يستتتج العلاقة بين عناصر ونظام البيئة الساحلية. r. بعي أهمية البيئة الساحلية للسكان المحيطين. r. يقدر نعمة الله في الثروات التي نتحصل عليها من البيئة الساحلية. ع. يشارك في اتخاذ قرارات من شأنها الحفاظ على البيئة الساحلية.

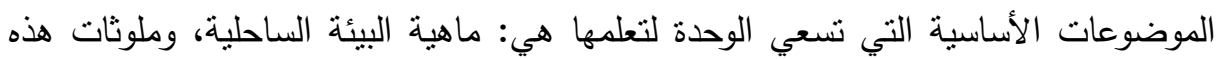

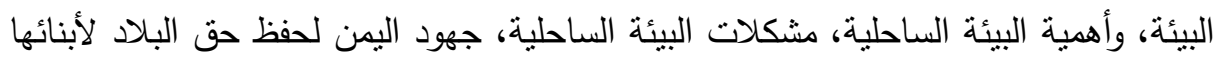
بعدم التعدي على بيئاتها الساحلية، خصائص البيئة الساحلية، مصادر النلوث في البيئة الساحلية، والآثار الناجمة عن كل مصدر من هذه المصادر، حيث نم تضمين المعارف لينا

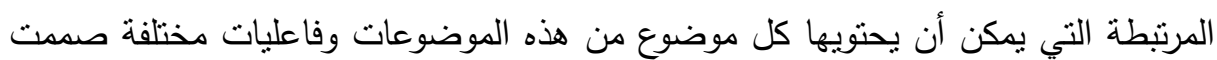
باستخدام استراتيجيات تعليم بشكل يتيح للطلاب كيفية اكتسابها وتعلمها.

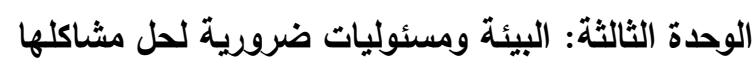

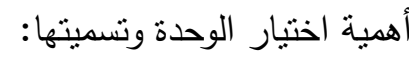
- ربط الطلاب بالقضايا والمشكلات البيئية في مجتمعهم الساحلي. - تعميق الثعور بالآثار الناجمة عن التلوث في البيئة الساحلية من خلال مواقف واقعية.

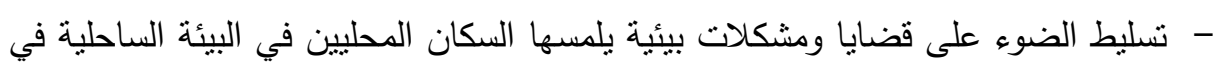
حياتهم اليومية أدعي لتجاوبه معها ولبقاء أثز التعلم في نفسه.

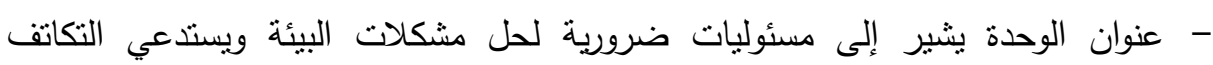
الإنساني لمعالجة الآثار الناجمة عنها، وكلها أمور تتطلب مسئولية يجب أنب أن يكتسبها الطلاب بكليات التربية ويتعلموها، اوحت بهذه التسمية للوحدة.

\section{الأهداف الإجرائية لتعلم هذه الوحدة:}

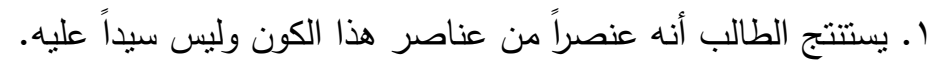
r. يفسر تصرفات الإنسان السلبية تجاه البيئة بأنها أعمالاً غير مسئولة. r. يضع خطة بيئية لتحسين جودة الحياة في البيئة الساحلية.

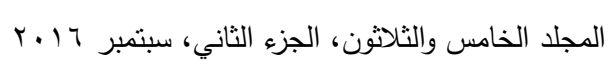


ع. يعي أهية التزام الإنسان بالمسئولية الثخصية تجاه البيئة المحيطة.

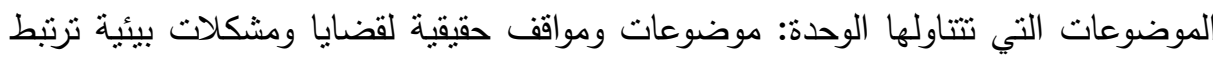
بالبيئة الساحلية حدثت في الجمهورية اليمنية وبالتحديد في بعض المحافظات الساحلية خلال السنوات الأخيرة، ولها تأثيرها المباشر علي صحة الإنسان، والكائنات الحية في البيئة

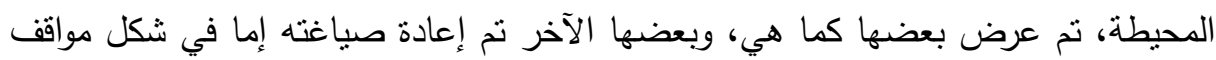

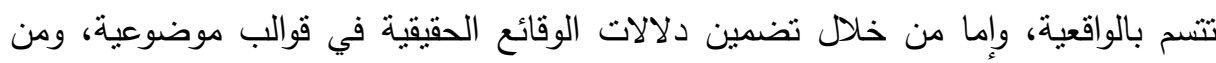
خلال عرض هذه المواقف البيئية يدرك الطلاب أن هذه المواقف التي أحدثت كل هذه الآثار السلبية هي رهن بسلوكه الغير مسئول تجاه البيئة وبطريقة تفاعله معها، حيث نستعرض هذه لهنه الوقائع التي ضمناها في سياقات أنشطة ندريبية مختلفة، مثل لو كنت أنت مسئولاً ماذا ستفعل؟ ونستقي منها المسئولية الواقعة على الطالب نفسه والتي أدت بغيابها لظهور هذه لنه المشكلات والآثار السلبية.

للإجابة على السؤال الرابع: "ما فاعلية البرنامج المقترح في تتمية المسئولية البيئية تجاه

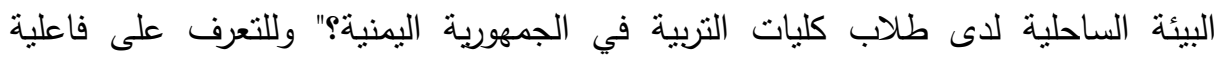
البرنامج المقترح في تتمية المسئولية البيئية تجاه البيئية الساحلية، كان لابد من إعداد مقياس

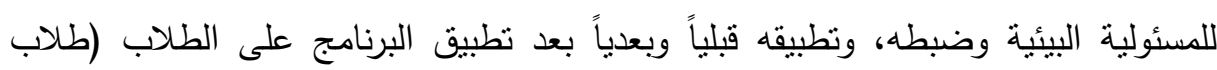
المجموعة التجريبية) وقد وجد البحث الحالي أنه من المناسب ووفقاً لطبيعية المسئولية وأبعادها؛ أن يكون لكل بُعد مقياسه الفرعي في بنوده ودرجاته؛ وبناء على ذلك فقد بلغ عدد البد أبعاد المقياس ثناثة أبعاد على النحو التالي: البعد الأول: المعرفة بعناصر البيئة الطبيعية: ويقصد به " مدى فهم الطلاب للمشكلات

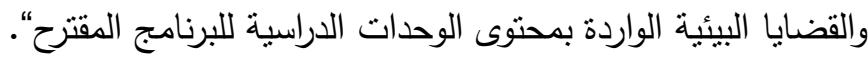
البعد الثاني: سلوكيات بيئية مسئولة: ويقصد به " مدى ممارسة الطلاب لسلوكيات متعلقة بييئتهم الساحلية باليمن أثناء تعاملهم معها في حياتهم العملية". البعد الثالث: الاتجاهات البيئية الإيجابية نحو البيئة الساحلية: ويقصد به " مدى ما يدركه الطلاب عن أهية الحفاظ على البيئة الساحلية، كما يعكس مدى اهتمامهم بالجهود الإئه 
المبذولة لمكافحة التلوث البيئي في البيئة الساحلية، فضلاً عن أهمية دراسة الموضوعات والمشكلات البيئية المرتبطة بسواحل البيئة اليمنية من خلال الوحدات الدراسية ". وكانت الصورة النهائية للمقياس كالتالي: تكونت الصورة النهائية للمقياس بعد إجراء التعديلات، من الآتي: أ- ورقة الأسئلة: وتتكون من صفحة الغلاف الخاص بكل بعد فرعي على حدة، ثم صفحة

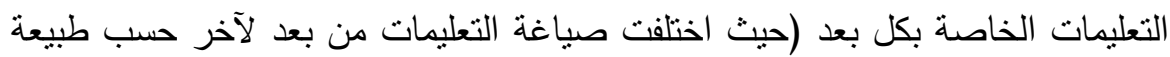

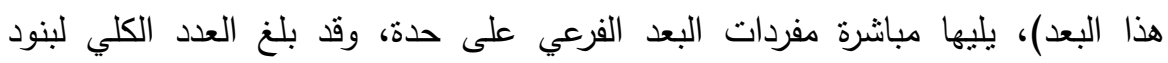

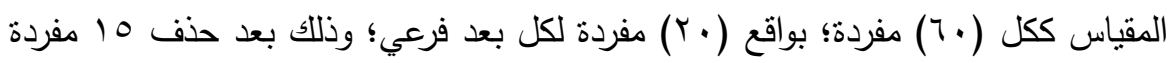
بواقع خمسة مفردات من كل بعد على حدة. ب- ورقة الإجابة: وبها أرقام مفردات كل بعد من أبعاد المقياس، وأمام كل بند استجاباته الخاصة.

ت- طريقة التصحيح: ترصد درجة واحدة للإجابة الصحيحة، وصفر للإجابة الخطأ، وذلك

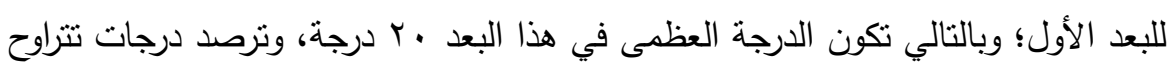

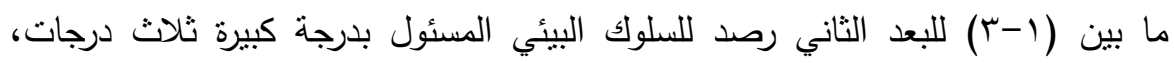
ودرجتان للسلوك البيئي المسئول بدرجة متوسطة، ودرجة واحدة للسلوك البيئي المسئول

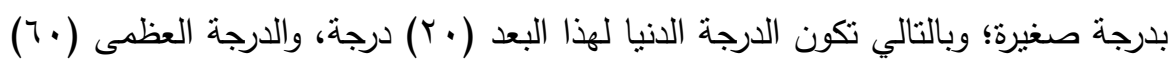
درجة؛ وبالنسبة للبعد الثالث فقد رصدت ثثلاث درجات للاستجابة موافق، ودرجتان

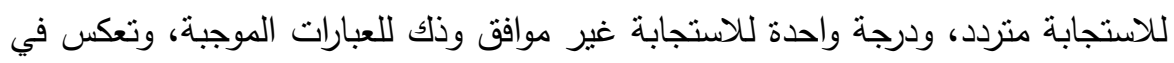

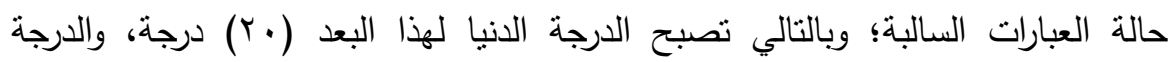

$$
\text { العظمى ( • (؟) درجة. }
$$

وعليه تصبح الدرجة العظمى لمقياس المسئولية البيئية (•ـ ()) درجة، والدرجة الدنيا

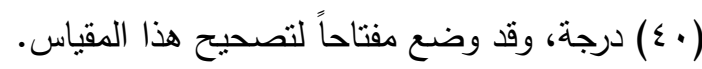


وهكذا يصبح مقياس المسئولية البيئية تجاه البيئة الساحلية لطلاب كليات التربية بالجمهورية اليمنية في صورته النهائية أداة صالحة للاستخدام والنطبيق للوقوف على مستوى لهن

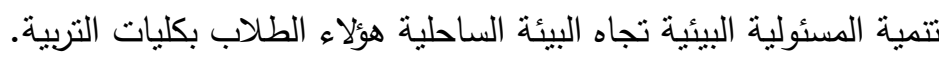

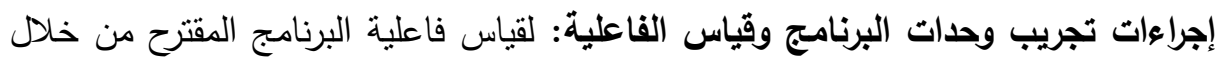
تجريب الوحدات الثلاث التي تم بناءُها وأدوات تقويمها، ثم تجريب الوحدات وتقويمها على لهي

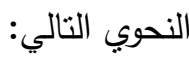

أ. حدود تجريب البرنامج: اقتصر تجريب برنامج تتمية المسئولية البيئية تجاه البيئة الساحلية على الثلاثة وحدات المعدة ومكونة من موضوعات المسئولية البيئية، والبيئة الساحلية، والنظام البيئي ومشكلاته؛ وعليه فإن نتائج البحث ستكون محصورة فئه في هذا الحد.

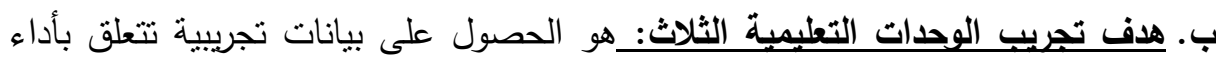
أفراد مجموعة البحث التجريبية من المجموعتين التجريبية والضابطة، وحساب الفرق بينهما، للتحقق من صحة فروض البحث؛ وبالتالي الحكم على فاعلية البرنامج المقترح في تتمية المسئولية البيئية تجاه البيئة الساحلية.

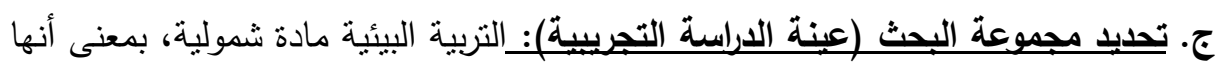

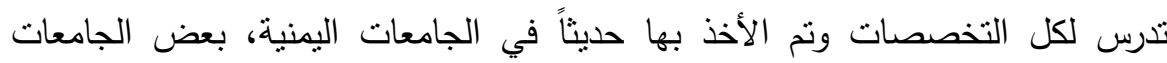
أدرجتها ضمن المواد الاختبارية كجامعتي الحديدة، وصنعاء، وتعز، والبعض الأخر

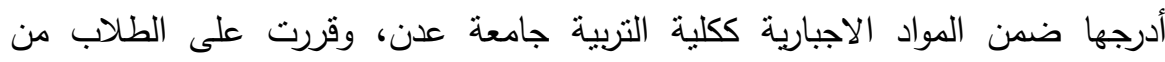
التخصصات المختلفة، وقد نم اختيار مجموعة البحث من الطلاب الدارسين في كلية التربية باجل- جامعة الحديدة، ومن المستوي الرابع، موضحين كالتالي: - طلاب كليات التربية جامعة الحديدة، وهي مدينة ساحلية، وكلية التربية باجل.

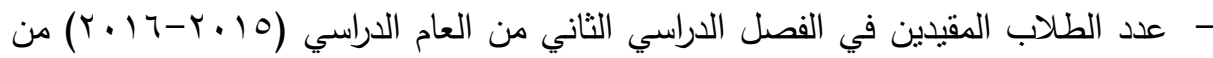
مختلف التخصصات (جغرافيا، تاريخ، كيمياء، احياء، رياضيات، ...) للمستويات الثاني والثالث الاختياري. - شكل هؤلاء الطلاب قوام مجتمع البحث وعينته. 
- قسم الطلاب عشوائياً إلى مجموعة تجريبية وتكونت من ( . ( ) طالباً من كلية التربية باجل، بجامعة الحديدة، وبذلك تكون إجمال المجموعة التجريبية ( . . (1) طالباً. تدريس الوحدات التجريبية من البرنامج: نم البدء في تدريس الوحدات الثناثة التجريبية والتي ولي

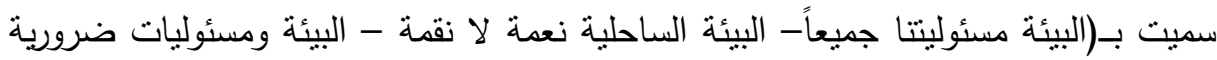

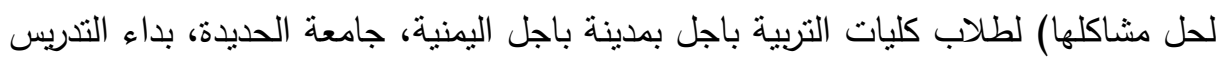

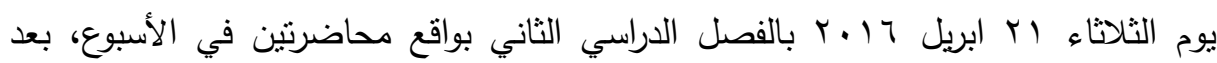

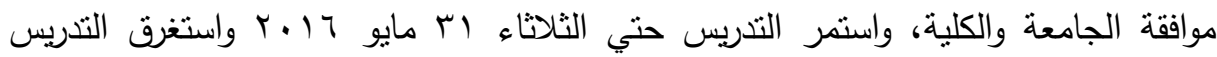
حوالي الثهر والنصف، ونم التدريس باستخدام طريقة المحاضرة واستراتيجية التعلم التعاوني، والهرئ والعصف الذهني.

\section{نمتائي الهميث}

وفيها نم إجراء التحليل الإحصائي باستخدام الأساليب الإحصائية المناسبة للنحقق من

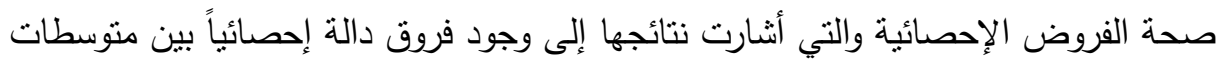
درجات الطلاب بالمجموعة التجريبية في التطبيقين القبلي والبعدي لمقياس المسئولية البيئية؛ الأمر الذي يشير إلى فاعلية البرنامج المقتزح لتتمية المسئولية البيئية تجاه البيئة الساحلية لطلاب كليات التربية في الجمهورية اليمنية، وتتمثل النتائج التي توصل إليها البحث فيما يلي:

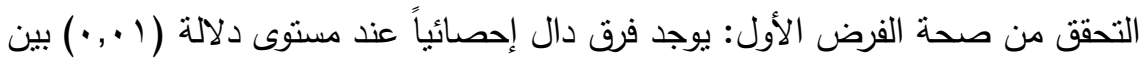
متوسطي درجات المجموعة التجريبية (القبلي والبعدي) على بعد المعرفة بعناصر البيئة دلئ الطبيعية بعد تطبيق البرنامج المقترح لصالح التطبيق البعدي.

ولاختبار صحة هذا الفرض نم الاستعانة ببرنامج SPSS الإحصائي؛ حيث نم تطبيق لئيق اختبار (ت) للعينة التجريبية على درجات الطلاب في التطبيق القبلي والبعدي لمقياس المسئولية البيئية (لبعد المعرفة بعناصر البيئة الطبيعية)، وحساب المتوسط الحسابي والانحراف

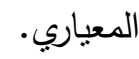


ويوضح الجدول التالي(r) نتائج التطبيق وقيم (ت) كما يلي: جدول(ץ): نتائج التطبيق القبلي/ البعدي لمقياس المسئولية البيئية بعد المعرفة بعناصر البيئة الطبيعية على مجموعة البحث (ن = . . . 1 طالب)

\begin{tabular}{|c|c|c|c|c|c|c|c|c|c|}
\hline \multirow{2}{*}{ التأثبر } & \multirow{2}{*}{ مستوى الدلالة } & \multirow{2}{*}{ الحرية } & \multirow{2}{*}{ قتيمة } & \multicolumn{2}{|c|}{ التطبيق البعدي } & \multicolumn{2}{|c|}{ التطبيق القبلي } & \multirow{2}{*}{ العظمي } & \multirow{2}{*}{ البعد } \\
\hline & & & & r & ק & ع & ما & & \\
\hline$r, Y^{\prime}$ & دالة, & 99 & 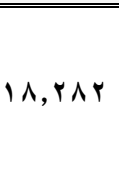 & $1, r r$ & $10, \leqslant 1$ & \&, \&१ & 7,11 & $r$. & البغناصرفة \\
\hline
\end{tabular}

ولاختبار تحقق هذا الفرض تم رصد درجات الطلاب -مجموعة البحث -في بعد المعرفة بعناصر البيئة الطبيعية، وإيجاد قيمة (t-test) لاختبار دلالة الفروق بين متوسط درجات الطلاب فى النطبيق القبلي والبعدي لمقياس المسئولية البيئية. وبحساب المتوسطات الحسابية لبعد المعرفة بعناصر البيئة الطبيعية البيئية، حيث تم توزيع عشرون مفردة من ثلاثة أبعاد رئيسة للمقياس ككل، ومن خلال النتائج المبينة في الجدول رقم (r) تبين أنه يوجد فرق ذو دلالة إحصائية لبعد (المعرفة بعناصر البيئة الطبيعية)

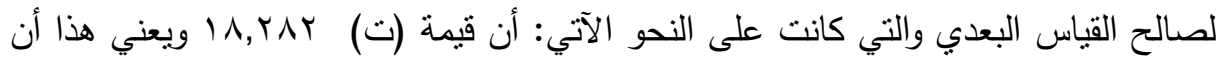
هناك فروق ذات دلالة إحصائية بين متوسطي درجات أفراد العينة على القياس القبلي والبعدي البي

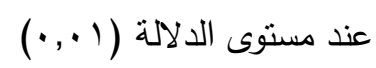

وللتأكد من ذلك نم مقارنة القيمة العملية (القيمة التائية) من الجدول السابق

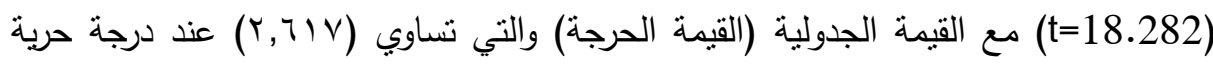
df= 99

$$
\text { الجدولية (الحرجة). }
$$

وهذا يدل على أن هناك فروق ذات دلالة إحصائية بين متوسطي درجات أفراد العينة على القياس القبلي والبعدي على مقياس المسؤولية البيئية تجاه البيئة الساحلية (البعد الأول)

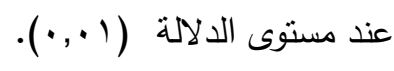


حيث كان المتوسط البعدي (1) (10,1) أكبر من المتوسط القبلي (1) (7,1)، وقد بلغ حجم الأثر (Y,Y (Y). مما يدل على وجود أثراً كبيراً للبرنامج على تتمية بعد المعرفة بعناصر البيئة الطبيعية من أجمالي مقياس المسئولية البيئية. المعرفة بعناصر البيئة الطبيعية

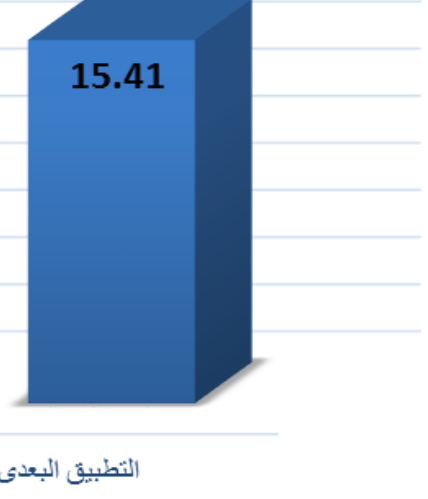

شكل(1): نتائج التطبيق القبلي / البعدي لبعد المعرفة بعناصر البيئة الطبيعية

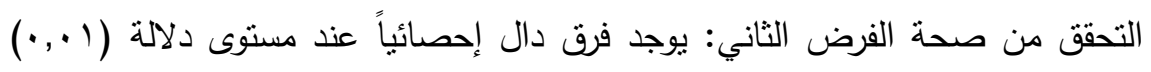
بين منوسطي درجات المجموعة التجريبية (القبلي والبعدي) على بعد سلوكيات بيئية مسئولة بعد تطبيق البرنامج المقترح لصالح التطبيق البعدي. ولاختبار صحة هذا الفرض تم الاستعانة ببرنامج SPSS الإحصائي؛ حيث نم تطبيق لبنيق

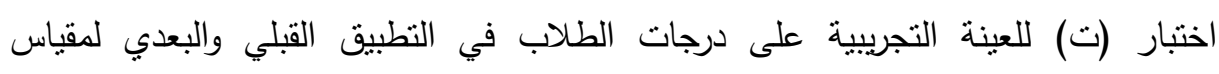

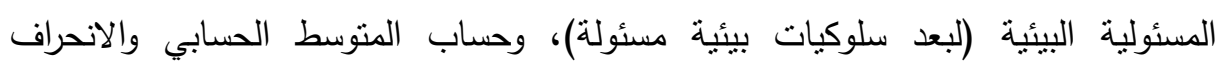
المعياري. 


$$
\text { ويوضح الجدول التالي (ء) نتائج التطبيق وقيم (ت) كما يلي: }
$$

جدول(§): نتائج التطبيق القبلي/ البعدي لمقياس المسئولية البيئية بعد سلوكيات بيئية مسئولة

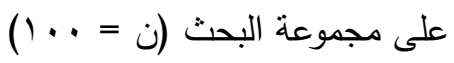

\begin{tabular}{|c|c|c|c|c|c|c|c|c|c|}
\hline \multirow{2}{*}{ التأثير } & \multirow{2}{*}{ الدلالة } & \multirow{2}{*}{$\begin{array}{c}\text { لرجات } \\
\text { الحرية }\end{array}$} & \multirow[b]{2}{*}{ قيمة ت } & \multicolumn{2}{|c|}{ التطبيق البعدي } & \multicolumn{2}{|c|}{ التطبيق القبلي } & \multirow{2}{*}{ العظمي } & \multirow[b]{2}{*}{ البعد } \\
\hline & & & & $r \varepsilon$ & p & ' & pl & & \\
\hline$r, \wedge \wedge$ & دالة, & 99 & $\begin{array}{c}1 \cdot, 1 \leqslant \\
9\end{array}$ & 1,104 & $\varepsilon \Lambda, Y r$ & 1,19 & $|v, 7|$ & 7. & سبئية \\
\hline
\end{tabular}

ولاختبار تحقق هذا الفرض تم رصد درجات الطلاب -مجموعة البحث- في بعد المعرفة بعناصر البيئة الطبيعية، وإيجاد قيمة (t-test) لاختبار دلالة الفروق بين متوسط درجات الطلاب في التطبيق القبلي والبعدي لمقياس المسئولية البيئية. وبحساب المتوسطات الحسابية لبعد سلوكيات بيئية مسئولة، حيث تم توزيع عشرون لهنية

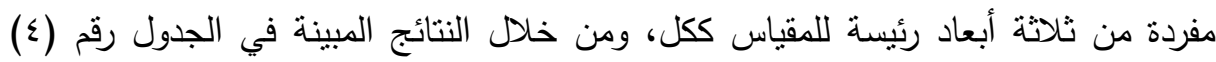
تنين أنه يوجد فرق ذو دلالة إحصائية لبعد (سلوكيات بيئية مسئولة) لصالح القياس البعدي والتي كانت على النحو الآتي:

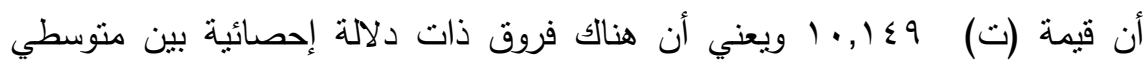
درجات أفراد العينة على القياس القبلي والبعدي عند مسنوى الدلالة ( ( . .•).

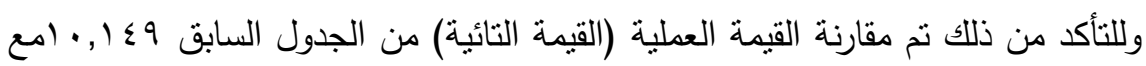

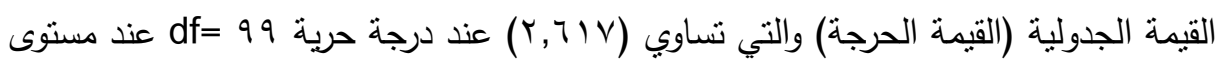
الدلالة ( ا... ) ومن ثم نجد أن القيمة العملية أكبر من القيمة الجدولية (الحرجة). وهذا يدل على أن هناك فروق ذات دلالة إحصائية بين متوسطي درجات أفراد العينة على القياس القبلي والبعدي على مقياس المسؤولية البيئية تجاه البيئة الساحلية (البعد الثاني) عند مستوى الدلالة (1 (., (•). 


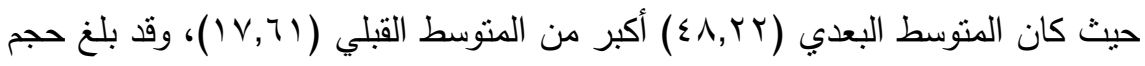
الأثر (广,^^). مما يدل على وجود أثراً كبيراً للبرنامج على تتمية بعد سلوكيات بيئية مسئولة من أجمالي مقياس المسئولية البيئية.

\section{سلوكيات بيئية مسئولة}

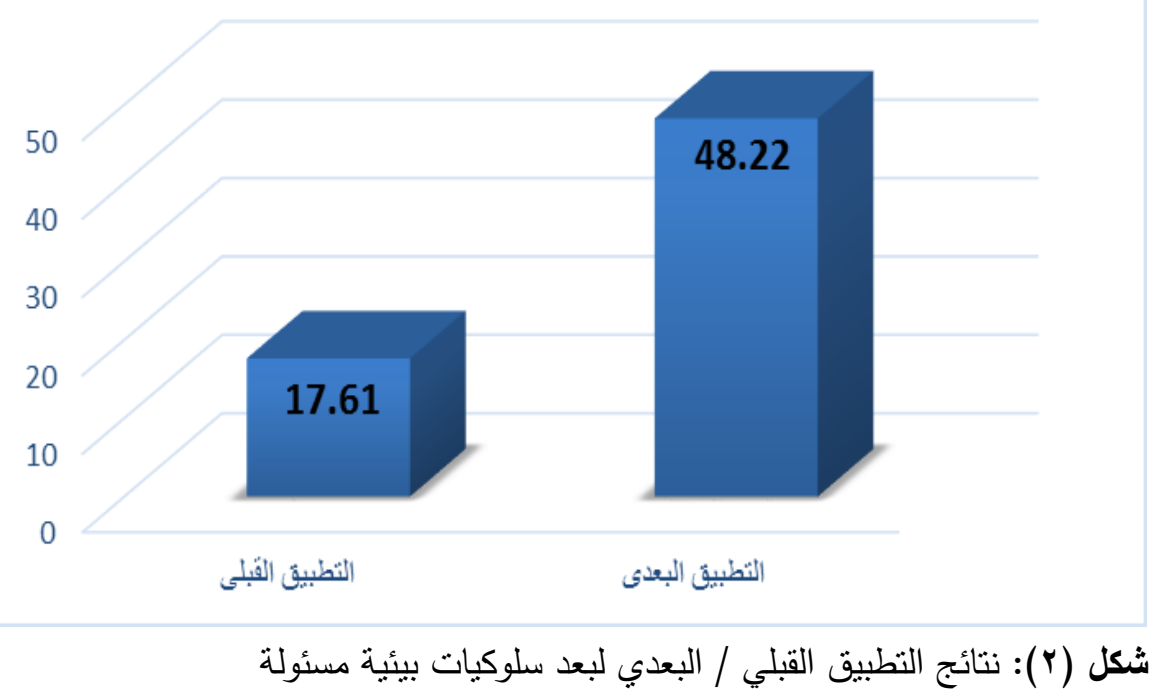

التحقق من صحة الفرض الثالث: يوجد فرق دال إحصائياً عند مستوى دلالة (1 (., ) بين متوسطي درجات المجموعة التجريبية (القبلي والبعدي) على بعد سلوكيات بيئية مسئولة بعد تطبيق البرنامج المقترح لصالح التطبيق البعدي. ولاختبار صحة هذا الفرض نم الاستعانة ببرنامج SPSS الإحصائي؛ حيث نم تطبيق اختبار (ت) للعينة التجريبية على درجات الطلاب في التطبيق القبلي والبعدي لمقياس المسئولية البيئية لبعد (الاتجاهات البيئية الإيجابية نحو البيئة الساحلية)،وحساب المتوسط الحسابي والاتحراف المعياري. 
ويوضح الجدول التالي (0) نتائج التطبيق وقيم (ت) كما يلي: جدول(ه): نتائج التطبيق القبلي/البعدي لمقياس المسئولية البيئية بعد الاتجاهات البيئية

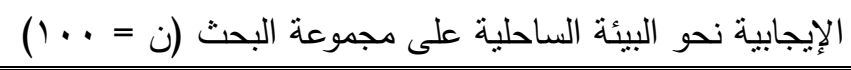

\begin{tabular}{|c|c|c|c|c|c|c|c|c|c|}
\hline \multirow[b]{2}{*}{ التأثير } & \multirow[b]{2}{*}{ الدلالةً } & \multirow{2}{*}{ لدرجات } & \multirow[b]{2}{*}{ قيمة ت } & \multicolumn{2}{|c|}{ التطبيق البعدي } & \multicolumn{2}{|c|}{ التطبيق القبلي } & \multirow{2}{*}{ العظمى } & \multirow[b]{2}{*}{ البعد } \\
\hline & & & & $r \varepsilon$ & $r_{p}$ & ' & ק' & & \\
\hline$\Gamma, q \vee$ & دالة & 99 & $0, V$ V & $\cdot, \wedge q$ & $0 ., 1 \leqslant$ & $r, 1 r$ & $17,0 \leqslant$ & 7. & الالإتجاهاتية البيئة نحو \\
\hline
\end{tabular}

ولاختبار تحقق هذا الفرض نم رصد درجات الطلاب -مجموعة البحث- في بعد المعرفة بعناصر البيئة الطبيعية، وإيجاد قيمة (t-test) لاختبار دلالة الفروق بين منوسط درجات الطلاب فى التطبيق القبلي والبعدي لمقياس المسئولية البيئية. وبحساب المتوسطات الحسابية لبعد الاتجاهات البيئية الإيجابية نحو البيئة الساحلية، حيث نم توزيع عشرون مفردة من ثناثة أبعاد رئيسة للمقياس ككل، ومن خلال النتائج المبينة في الجدول رقم (0) تبين أنه يوجد فرق ذو دلالة إحصائية لبعد (الاتجاهات البيئية الإيجابية

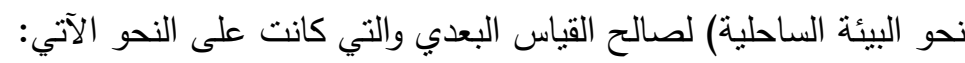

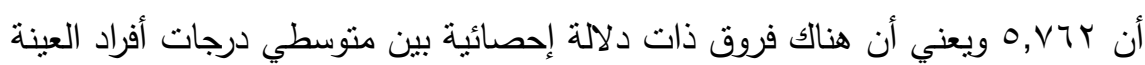

$$
\text { على القياس القبلي والبعدي عند مستوى الدلالة (1 ل. , •). }
$$

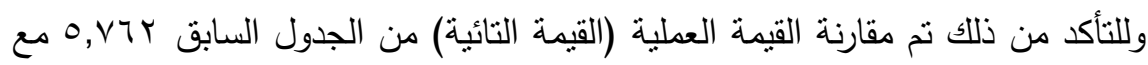

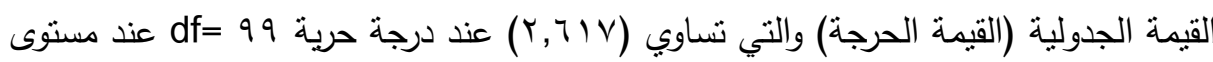

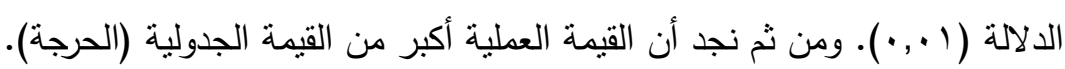

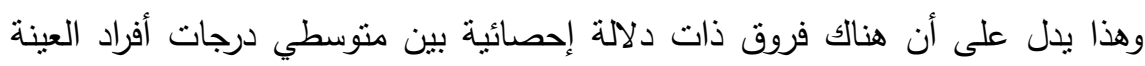
على القياس القبلي والبعدي على مقياس المسؤولية البيئية تجاه البيئة الساحلية (البعد الثالث)

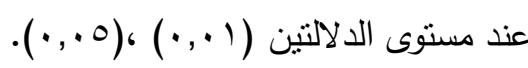

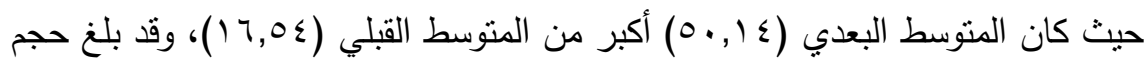




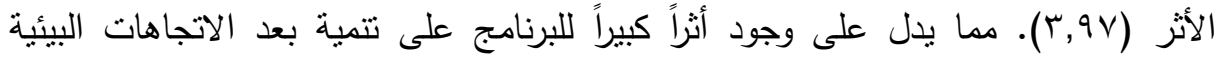
الإيجابية نحو البيئة الساحلية من أجمالي مقياس المسئولية البيئية.

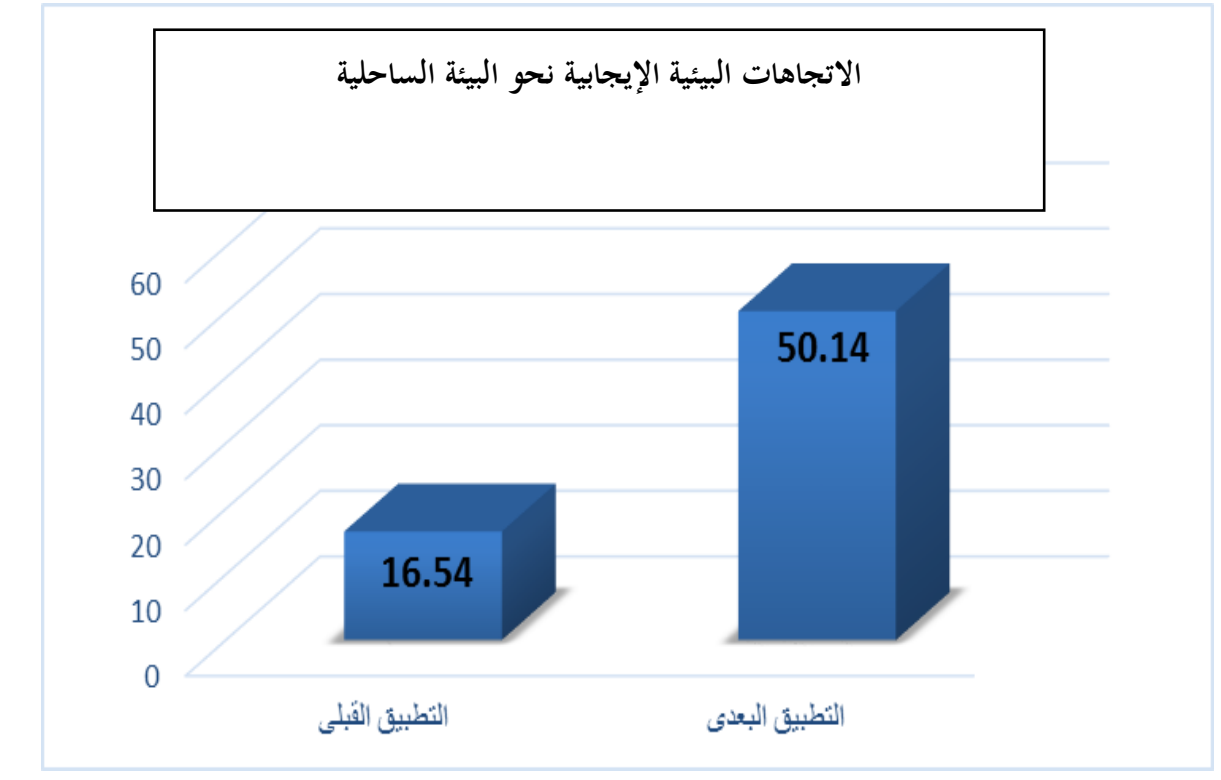

شكل(ץ): نتائج النطبيق القبلي / البعدي لبعد الاتجاهات البيئية الإيجابية نحو البيئة الساحلية في مقياس المسئولية البيئية (بأبعاده الثناثة) لئنة

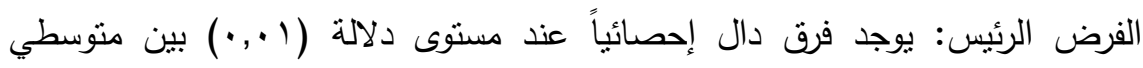
درجات المجموعة التجريبية (القبلي والبعدي) على مقياس المسئولية البيئية وكافة أبعاده المقترحة بعد نطبيق البرنامج المقترح لصالح النطبيق البعدي. ومن خلال التحقق من صحة الفروض الثالثة السابقة، والتي تمثل المقياس ككل أمكن تحديد دلالة الفروق بين متوسطي درجات المجموعة التجريبية في التطبيق القبلي والبعدي لمقياس المسئولية البيئية بأبعاده الثلاثة. لمنئ. 
جدول(7): قيم (ت) لالالة الفروق بين متوسطي درجات المجموعة التجريبية في التطبيق القبلي والبعدي لمقياس المسئولية البيئية بأبعاده الثناثة (ن= دل . . ( )

\begin{tabular}{|c|c|c|c|c|c|c|c|c|c|}
\hline ألالة & $\begin{array}{l}ت \\
\mathbf{T}\end{array}$ & لرجات & للفرياري & الفروق & $\varepsilon$ & r & القياس & البعد & الأبعاد \\
\hline \multirow[t]{2}{*}{ دالة } & \multirow[t]{2}{*}{ IA, rAr } & \multirow[t]{2}{*}{99} & & & $\leqslant, \leqslant 9$ & 7,11 & قبلي & \multirow[t]{2}{*}{$r}$. & بعناصر \\
\hline & & & & & $1, r r$ & $10, \leqslant 1$ & بعدي & & الطبيعية \\
\hline \multirow{2}{*}{ دالة } & \multirow{2}{*}{$1 \cdot, 1 \leq 9$} & \multirow{2}{*}{99} & & & 1,19 & $|V, T|$ & قبلي & \multirow{2}{*}{7.} & سلوكيات \\
\hline & & & & & 1,10 & $\varepsilon \Lambda, r r$ & بعدي & & مسئولة \\
\hline \multirow[t]{2}{*}{ دالة } & \multirow[t]{2}{*}{ D,VTr } & \multirow[t]{2}{*}{99} & & & $r, i r$ & $17,0 \leq$ & قبلي & \multirow[t]{2}{*}{7.} & نحو البيئة \\
\hline & & & & & $\cdot, \wedge 9$ & $0 ., 1 \leq$ & بعدي & & الساحلية \\
\hline \multirow{2}{*}{ دالة } & \multirow{2}{*}{17,911} & \multirow{2}{*}{99} & \multirow{2}{*}{$0, Y 17$} & \multirow{2}{*}{ YY,YY } & $r, Y$. & $\varepsilon \cdot, Y q$ & قبلي & \multirow{2}{*}{$1 \leqslant}$. & إجمالي \\
\hline & & & & & $1, .9$ & $\| \mu, v V$ & بعدي & & المقياس \\
\hline
\end{tabular}

يتضح من النتائج السابقة وجود فروق ذات دلالة احصائية بين التطبيق القبلي والبعدي للمجموعة التجريبية (مجموعة البحث) وذللك في أبعاد مقياس المسئولية البيئية (بعد المعرفة بعناصر البيئة الطبيعية، وبعد سلوكيات بيئية مسئولة، وبعد الاتجاهات البيئية الإيجابية نحو البيئة الساحلية)، وكنللك في المقياس ككل حيث كانت ت المحسوبة = (7,9 1 وبمقارنتها

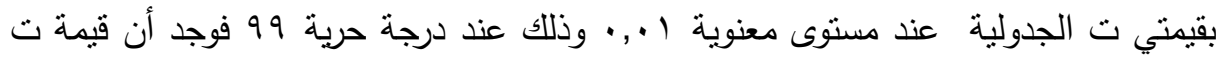

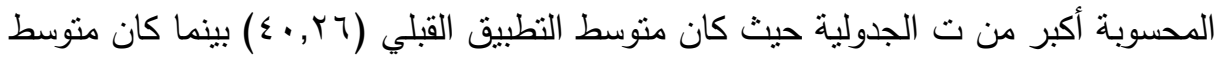

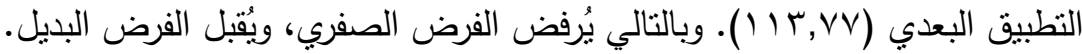
وهذا يدل على أن هناك فروق ذات دلالة إحصائية بين متوسطي درجات أفراد العينة على الاختبار القبلي والبعدي على مقياس المسؤولية البيئية تجاه البيئة الساحلية (المقياس ككل) عند مستوى الدلالة (1 ., ••) 


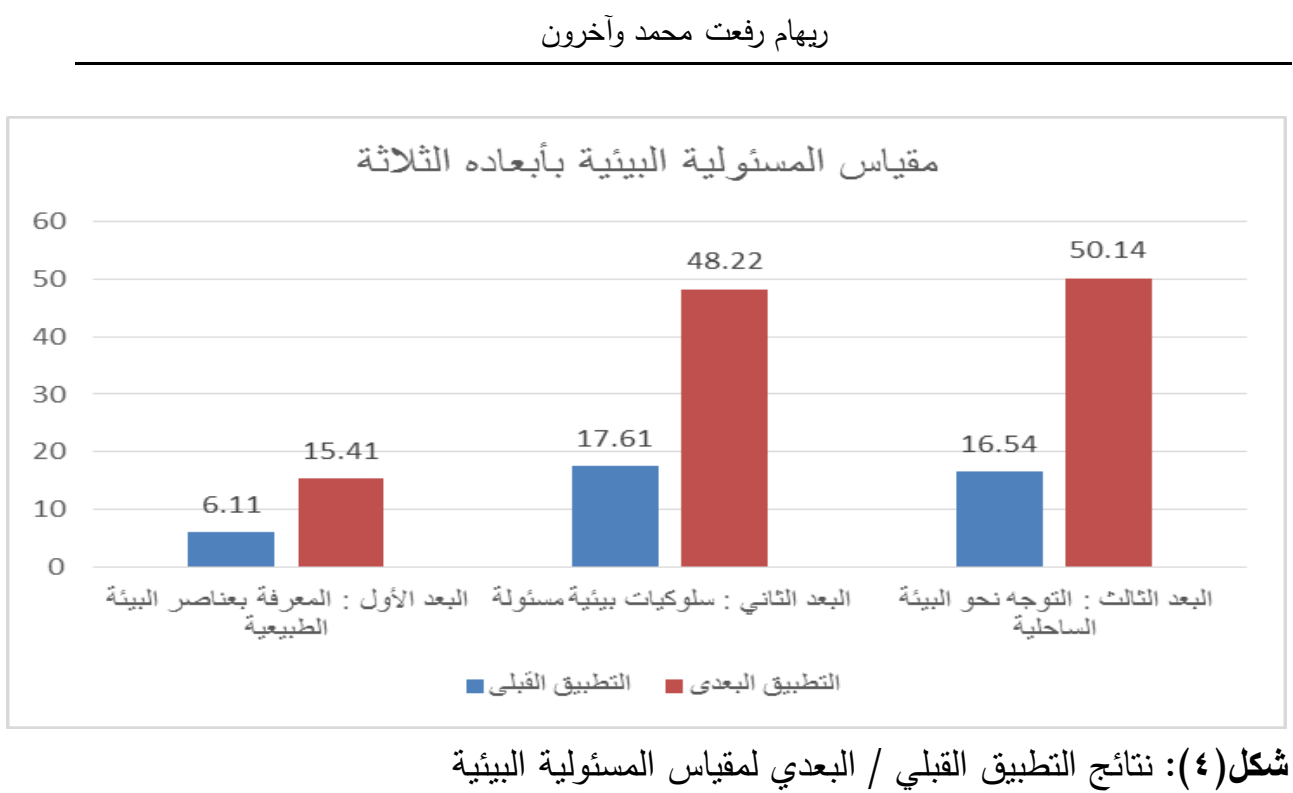

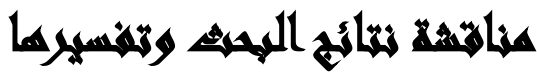

من خلال إثبات تحقق فروض البحث وتحليل النتائج أمكن استخلاص مجموعة من النقاط يمكن عرضها على النحو النالي:

• اتاحت موضوعات البرنامج المقترح الفرصة أمام الطلاب للمشاركة فى حل مشكلات بيئاتهم بصفة عامة والساحلية بصفة خاصة.

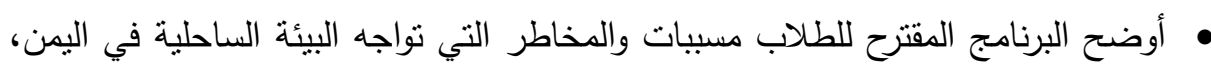
وطرق الوقاية منها وايضاً تتميتها. • أثنار البرنامج المقترح لبعض السلوكيات الخاطئة تجاه التعامل مع البيئة الساحلية من قبل الأفراد وأثنارها على البيئة، وكيفية تجنبها. 
من خلال الدراسات ذات الصلة بالموضوع فإن البحث الحالي يتقق في هذه النتائج مع

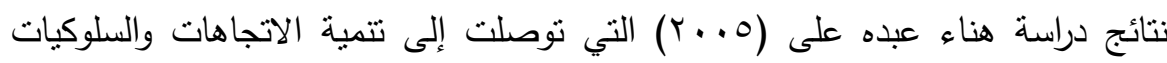
البيئية المرغوبة لدى طلاب كليات التربية، وكذلك نتائج دراسة محمد أحمد الأمير

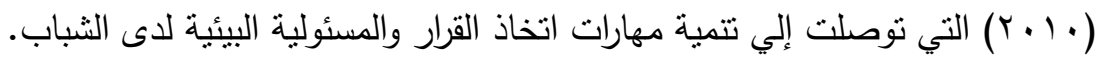
• نتوع الاستراتيجيات المستخدمة أثناء تدريس البرنامج، ساهم في تتمية المسئولية البيئية،

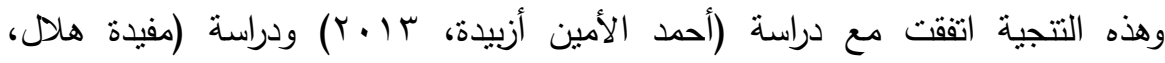
.$(Y \cdot V$

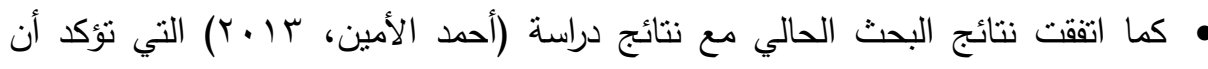

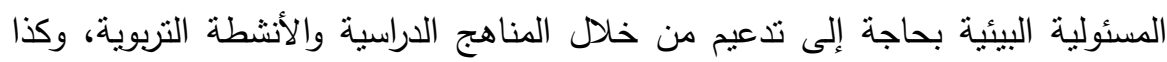

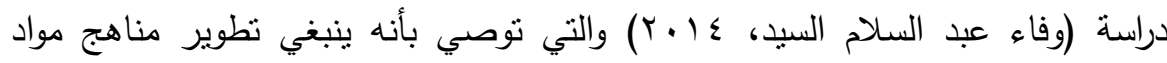

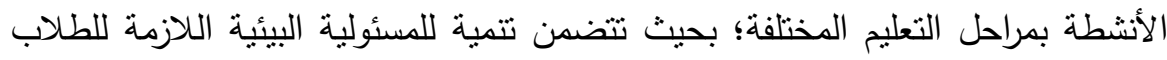
لتساعدهم على مواكبة التغيرات العصرية البيئية وكيفية التعامل مع المشكلات البيئية.

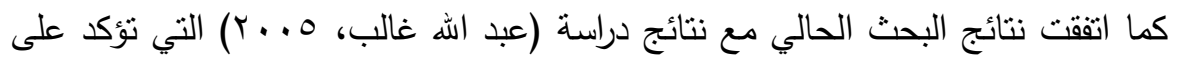

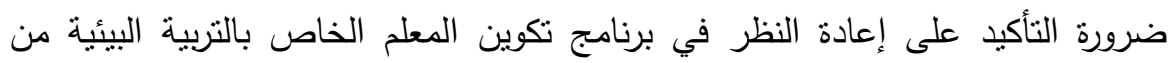

$$
\text { حيث: }
$$
- تحديد أهداف التربية البيئية في الجمهورية اليمنية، وتنني جميع الكليات لها وتدريسها في جميع كليات التربية. - - جعل مادة التربية البيئية مقراً إجبارياً وليس اختيارياً. - مكليف متخصص بتدريس التربية البيئية. - التركيز على الأنشطة التعليمية داخل وخارج كليات التربية. 
• كما اتفقت نتائج البحث الحالي مع نتائج دراسة (نور الدين أحمد ، . . r) التي تؤكد

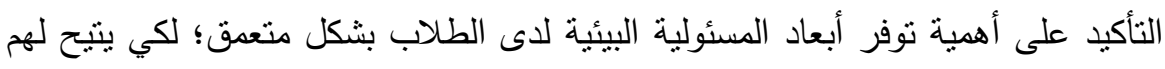
تصرفاً سليماً حيال المشكلات والقضايا البيئية المستجدة في بيئتهم المحلية، وأيضاً أهمية التأكيد على النواحي الوجدانية والمهارية والسلوكية عند تتفيذ برامج التربية البيئية، وعدم

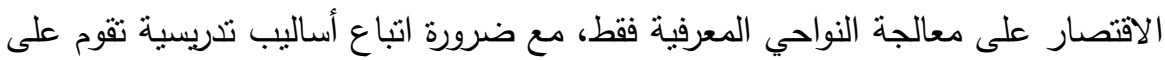
إيجابية وفاعلية المتعلم، وتدعيم ذلك بأنشطة ووسائل تعليمية متتوعة وفعالة تسهم في تحقيق وتتمية المسئولية البيئية بشتى أبعادها ومستوياتها.

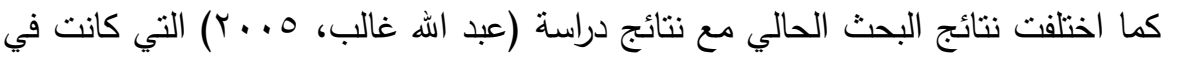
عدم وجود فرق دال احصائياً عند مستوى دلالة (0.,.) بين منوسطي درجات طلاب دراب

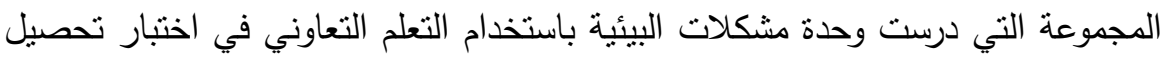
الثقافة البيئية، ولكن البحث الحالي كان للتعلم التعاوني تأثير في اكتساب الطلاب سلوكيات بيئية مسئولة تجاه البيئة الساحلية ومشكلاتها.

\section{تمكياهت المهيد}

في ضوء ما توصل اليه البحث من نتائج يمكن تقديم التوصيات الاتية:

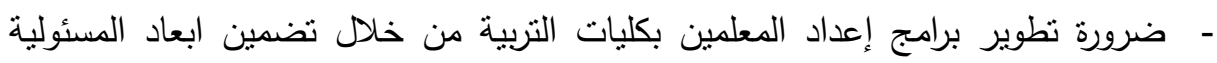
البيئية في المقررات التي يدرسها الطلاب خلال اعدادهم في كليات التربية في الجمهورية اليمنية. - الاهتمام بإعداد برامج لتتمية المسئولية البيئية تجاه البيئة الساحلية والاهتمام بغرس أبعادها على اختلافها لدي الطلاب في اليمن من خلال الممارسات الحياتية في بيئاتهم المحلية.

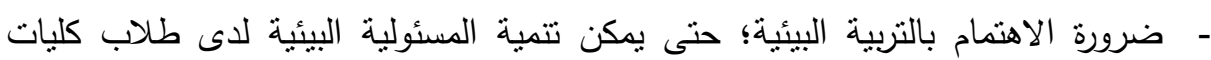
التربية في الجمهورية اليمنية. 


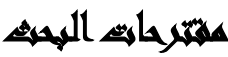

يقترح إجراء دراسات وبحوث في المجالات الآتية، مثل: ا. بحوث مماتلة للبحث الحالي تتناول عينات مختلفة من مراحل التعليم العام، وقياس أثرها في تنمية المسئولية البيئية لديهم. r. بحوث تستهدف تتمية السلوك البيئي المسئول من خلال برامج قائمة على مهارات التعامل مع مخاطر ومشكلات البيئات الساحلية. r. اجراء دراسات لقياس اتجاهات الطلاب نحو مسئولياتهم في تحمل واجباتهم الثخصية تجاه

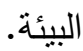
ع. بناء برامج في التربية البيئية لطلاب التعليم العام في ضوء المشكلات والقضايا البيئية في

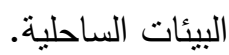

\section{المرالئ}

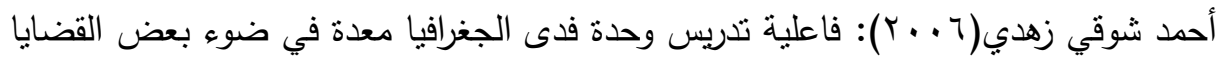

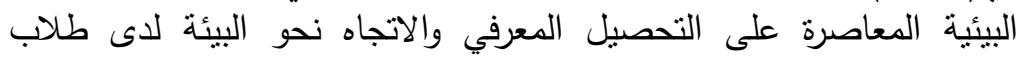
الصف الأول الثانوي، رسالة ماجستير ، كلية التربية، جامعة المنيا.

برنامج الأمم المتحدة الإنمائي(ب991): دليل برنامج الأمم المتحدة الإنمائي للإدارة البيئية

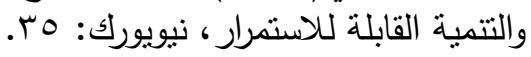

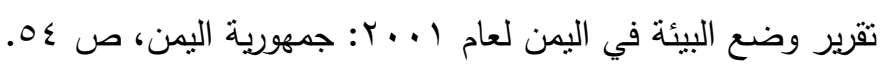

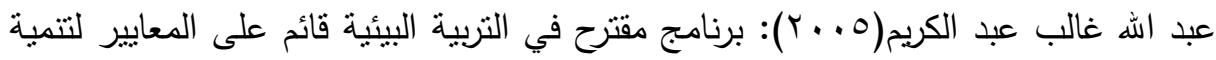

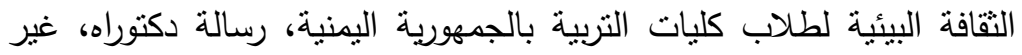

$$
\text { منشورة، كلية التربية، جامعة الإسكندرية. }
$$

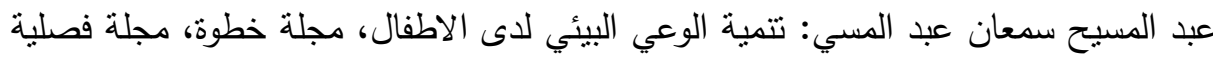

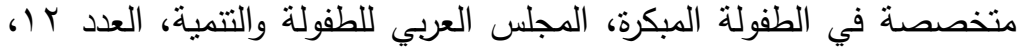

$$
\text { سبتمبر r... T) }
$$

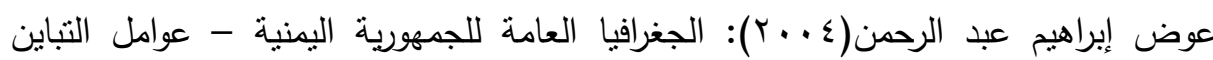
والتآلف في البيئة الينية، سلسلة إصدارات جامعة صنعاء رقم (^)، اليمن.

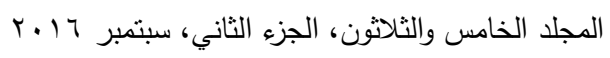


محمد أحمد الأمير القاضي(• ( • ب): فاعلية برنامج قائم على التعلم الذاتي باستخدام الحقائب

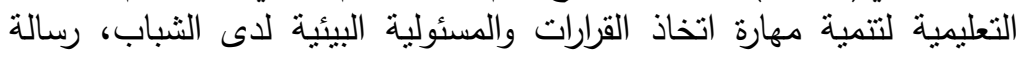
دكتوراه، معهد الدراسات والبحوث البيئية، جامعة عين شمس.

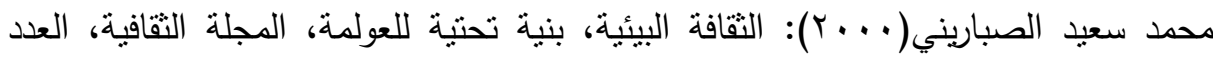

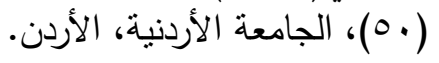

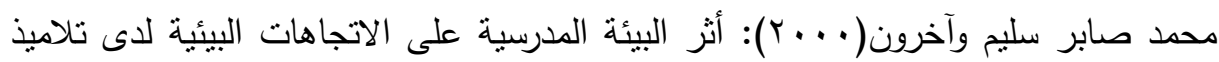

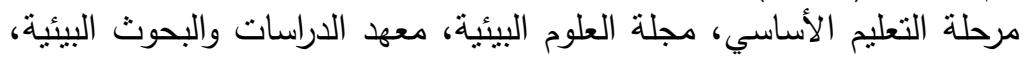

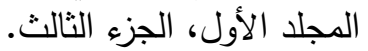

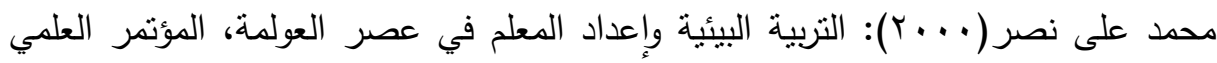

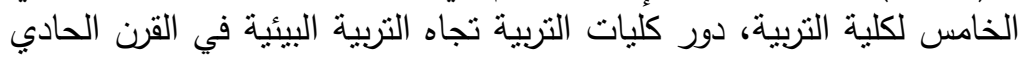

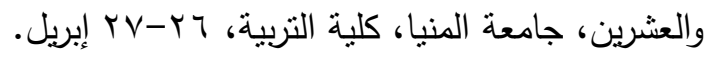

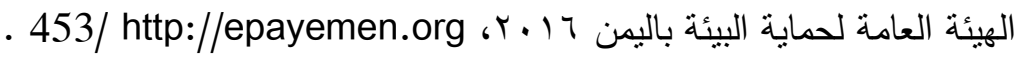

وفاء عبد السلام السيد(؟ ( ب): تتمية المسئولية البيئية لطلاب الأقسام النوعية بكلية التربية

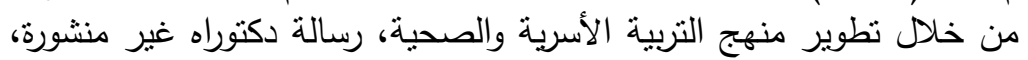
معهد الدراسات والبحوث البيئية، جامعة عين شمس.

Ebro, A., Her shay, J., and Veining, J. (2004): Reducing solid waste Linking Environmentally Responsible consumerism, Environment and Behavior, Recycling to vol. 31, No. $1 \mathrm{P}$. $474-479$.

Wilson, Ruth A. (1996): Starting Early Environmental Education During the Early Childhood Years (ERIC Digest). Columbus, OH: ERIC Clearinghouse for Science, Mathematics and Environmental Education (ERIC Identifier ED 402147). 
مجلة العلوم البيئية

معهذ الدراسات والبحوث البيئية - جامعة عين شمس البئ

\title{
A PROPOSAL FOR THE DEVELOPMENT OF ENVIRONMENTAL RESPONSIBILITY TOWARDS STUDENTS AT COLLEGES OF EDUCATION IN THE REPUBLIC OF YEMEN COASTAL ENVIRONMENT PROGRAM
}

Abdel Aal, Reham, R. ${ }^{(1)}$; Al Mohn, A. H. ${ }^{(2)}$ and Aqeeli, A. A. 1) Institute of Environmental Studies and Research, Ain Shams University 2) Faculty of Education, Arheb, Sana'a University

\begin{abstract}
The researchs aim to develop Environmental Responsibility towards the coastal environment among students in colleges of education in The Republic of Yemen through a proposed program. They prepare a list of issues and environmental problems associated with coastal environment through research literature found on previous studies and prepare an initial list were presented to experts and specialists, thus reaching a final list of problems with the boss, Environmental problems associated with coastal and great priority in accordance with the views instructions of the arbitrators. Then set up and program design based on the events and activities of the students in the faculties of education and several field activities to several sites related to the problems of the coastal environment through modules include program in environmental education decision.

As a measure of environmental responsibility is set towards the coastal environment, the scale of three dimensions are: Knowledge of the elements of the natural environment., be of (20) Single. Responsible environmental behavior, be of (20) Single. Towards the coastal environment, be of (20) Single.
\end{abstract}

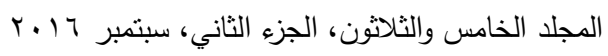




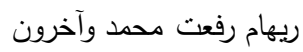

The Research group consisted of 100 students from the Faculty of education, Faculty of Education University of Hodeidah governorate of Hodeidah. Where is the software application and measure its impact by applying a scale three dimensions of environmental responsibility on them after being exposed to the program, analyze the data and draw conclusions.

The research concluded: his proposed program effectively, and had an impact on the development of environmental responsibility towards the coastal environment to solve their problems and to maintain and develop. 